\title{
ESTUDOS
}

\section{A divisão interna do campo universitário: uma tentativa de classificaçã̃o}

\section{Maria da Graça}

Jacintho Setton

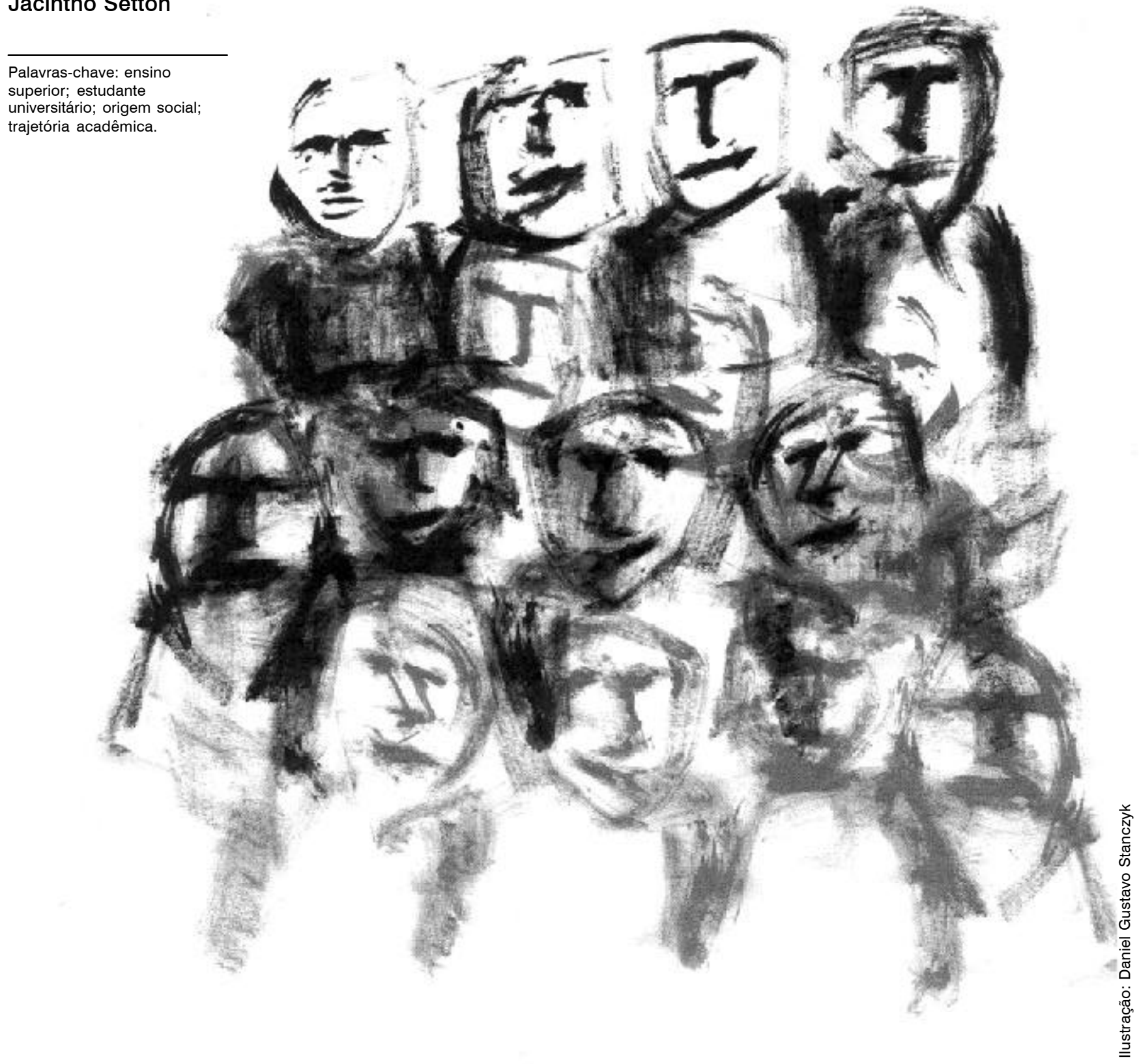




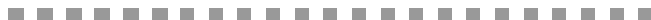

$\mathrm{R}$ hierarquização dos cursos universitários de Humanidades da Universidade de São Paulo (USP), a partir da análise da origem social e trajetória acadêmica de seus alunos. A análise das características socioculturais do estudantado permitiu observar que existe uma classificação velada dos cursos investigados. Mais do que isso, demonstra que existe uma correspondência entre as diferenças de recursos dos alunos e a procura por determinados cursos e carreiras. Trata-se de um esforço de compreensão do campo universitário e de parte dos agentes que o compõem.

\section{Introdução}

É comum tratarmos os estudantes universitários como uma categoria social, um conjunto de indivíduos jovens, com futuro promissor, protagonistas de trajetórias ascendentes, pouco diferenciados. Não obstante, as informações que obtivemos ajudam-nos a construir um outro perfil do estudante universitário e criticar o que há de estereótipo nessas imagens.

A respeito das origens socioculturais dos estudantes universitários desde a década de 60, os trabalhos de Pierre Bourdieu vêm orientando o debate. Com o clássico estudo Los estudiantes y la cultura (Bourdieu, Passeron, 1967) e uma série de artigos posteriores (Bourdieu, 1979a, 1980, 1983; Bourdieu, Passeron, 1982; Catani, Nogueira, 1998), este autor contribuiu decisivamente para a desmistificação da ideologia da escola libertadora. $O$ ensino universitário seria o espaço por excelência para se medir as vantagens ou desvantagens culturais acumuladas nas trajetórias socioacadêmicas dos alunos. Ou seja, o ensino superior estaria destinado a uma clientela seleta. Para o autor, o ambiente familiar e experiências de valorização do saber escolar e extra-escolar adquiridas fora do sistema educacional formal são determinantes para uma maior ou menor disposição em relação aos bens culturais. Aspirações de carreira como a predisposição ao discurso escolar estão fortemente marcadas pelos condicionamentos sociais exteriores ao indivíduo. As oportunidades objetivas estruturalmente dispostas alimentam a subjetividade individual orientando uma atitude em relação ao futuro. Crítico em relação ao dispositivo pedagógico tradicional, Bourdieu denuncia o caráter conservador do sistema de ensino ao valorizar apenas o saber aristocrático próprio das frações burguesas da sociedade. Considerando como iguais alunos com origem social diferente, o sistema escolar faz apenas conservar os mecanismos que perpetuam as desigualdades de oportunidades. Para dar continuidade à sua função de conservação, basta apenas manter a lógica de sua organização. Isto é, ignorar as diferenças e transmitir um saber que apenas parte de sua clientela tem condições de aproveitar.

Não obstante, estudos mais recentes, tanto sobre a realidade francesa (Erlich, 1998; Galland, Oberti, 1996) quanto a brasileira (Nogueira et al., 2000), revelam pouco a pouco a mudança do perfil social do estudante universitário. Mais especificamente, os estudos que abordaram as características socioeconômicas dos estudantes ressaltam a origem privilegiada de todos eles, embora já façam alguma distinção entre áreas do conhecimento e origem social (Castro, 1968; Gouveia, 1968, 1972; Prandi, 1982; Schwartzman, 1992; Santos, 1996).

Hoje, a visão estereotipada do estudante do ensino superior público e, sobretudo, a veiculada pela mídia, é do aluno proveniente de famílias bem estabelecidas, com amplo suporte financeiro e que, portanto, podem e devem contribuir para o pagamento de mensalidades. A universidade pública é vista como uma instituição que 
É possível observar alguns trabalhos pioneiros, mas recentes, publicados em Nogueira (2000).

2 Embora trabalhemos com um número relativamente pequeno de alunos, consideramos que as informações obtidas possam servir como material de reflexão para outros universos.

3 As informações apresentadas neste paper foram coletadas, em dois momentos. Em 1997 em uma pesquisa sobre perfil acadêmico e social dos alunos da Faculdade de Filosofia, Letras e Ciências Humanas (FFLCH) da USP e em 1998-1999, em uma investigação mais ampla sobre as expectativas acadêmicas e profissionais dos estudantes de Humanidades da USP, desenvolvida pelo Núcleo de Apoio aos Estudos da Graduação (Naeg), da USP, com financiamento da Fundação Universitária para o Vestibular (Fuvest). No ato da matrícula tanto em 1997 como em 1998 foi aplicado um questionário que envolveu mais de $50 \%$ da população investigada. apenas privilegia os já privilegiados, em detrimento da grande maioria da população que ainda não foi atendida nos níveis de ensino fundamental e médio (A greve..., 2000; O impasse..., 2000; Pela universidade..., 2000). Pouco se sabe como uma parcela de estudantes provenientes de lares com níveis pouco distintivos de capital cultural e econômico chegam até a universidade. Qual a trajetória que empreenderam e que fizeram romper as determinações estruturais? ${ }^{1}$

Neste sentido, questionando essas informações, seria interessante salientar que, entre os vários fatores que caracterizam as unidades e cursos investigados, o que mais se destaca é a diferença entre as origens sociais dos estudantes. As diferenças de composição e volume de recursos sociais e culturais (capital econômico e capital cultural) dos alunos mostraram-se relevantes para a compreensão do universo.

Apesar de estarmos trabalhando com um universo academicamente homogêneo, estudantes de Humanidades da Universidade de São Paulo, a diversidade de trajetórias, as diferenças de habitus e herança cultural entre alunos despertaram indagações sobre as diferenciadas formas de acesso e as heterogêneas possibilidades de formação profissional. ${ }^{2}$ A variada composição da clientela dos cursos é bastante significativa e contribui para a polêmica questão de possibilidades de acesso ao ensino universitário. Não obstante, a nosso ver, essa ampliação de oportunidades não corrobora a idéia de democratização educacional. O que verificamos é uma expressiva divisão interna entre os cursos e expectativas de carreira, divisão essa que reflete as distintas oportunidades educacionais em uma sociedade de classes.

Este artigo tem como objetivo fazer uma reflexão sobre a relação entre a origem social e cultural dos estudantes e a opção por um curso universitário. Para tanto, será necessário considerar algumas informações sobre o perfil social e cultural dos estudantes investigados. ${ }^{3}$ Iremos nos dedicar a uma leitura comparativa, trabaIhando alguns indicadores sociais a fim de apreender as especificidades do público universitário. A intenção que orienta a análise é apontar tendências gerais, conhecer e comparar a origem social e a trajetória acadêmica da clientela dos cursos de Humanidades da Universidade de São Paulo.

\section{Uma tentativa de classificação}

Considerando algumas informações sobre origem social e trajetória acadêmica como potenciais indicadores de diferenças, podemos obter uma visão crítica a respeito da realidade do campo universitário, sua complexidade e desafios. Indicadores como renda familiar, ocupação e instrução paterna e materna, conhecimento de idiomas estrangeiros relacionados com fatores como idade do aluno, ano de conclusão do ensino médio e período de curso serão aqui analisados, pois oferecem indícios de tendências e o sentido da trajetória acadêmica dos alunos. Esses indicadores fornecem um material que possibilita a compreensão da realidade diferenciada vivida pelos estudantes, suas possibilidades de sucesso ou os usos diferenciados que fazem da universidade. Mais do que isso, a análise relacional desses indicadores permite-nos proceder a uma classificação dos cursos segundo a variação dos recursos sociais e culturais de sua clientela.

Para o desenvolvimento analítico desta questão, utilizamos basicamente as contribuições de Pierre Bourdieu. Consideramos o jovem estudante a partir das categorias deste autor, pois elas nos permitem compreendê-lo como um agente sujeito a forças materiais e simbólicas. Bourdieu (1983) tem uma concepção sistêmica do social, isto é, a estrutura social é vista como um sistema hierarquizado de poder e privilégio, determinado tanto pelas relações materiais como pelas relações simbólicas.

Para analisar as condições de estudo e de vida dos jovens, ou seja, o perfil social, privilegiamos, em primeira instância, sua origem social. Portanto, para a localização desses jovens no competitivo espaço social, observamos a desigual distribuição de recursos e poderes de cada um deles. Entendemos por recursos: capital econômico, capital cultural, capital social e capital simbólico. Assim, a posição que um determinado aluno (ou sua origem social) ocupa nessa geografia universitária é definida, então, segundo a posição que esse mesmo aluno ocupa nos diferentes campos ou fontes de poder social. Isto é, as posições serão definidas de acordo com o volume e a composição de capital (econômico, cultural e social) que cada um deles adquiriu e/ou incorporou. 


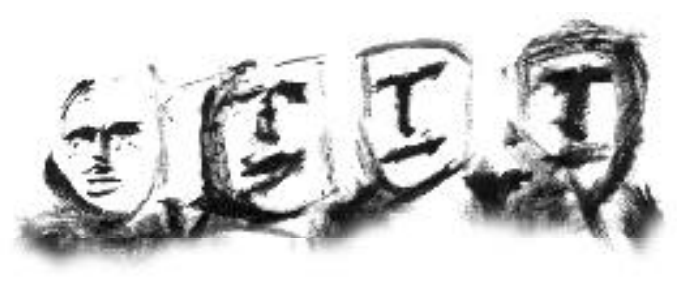

Bourdieu contribui, também, com sua leitura sobre os fenômenos culturais. Considera a cultura e os sistemas simbólicos em geral como instrumento de poder e, portanto, como legitimadores de uma ordem vigente. Para além de compreender os sistemas culturais apenas enquanto instâncias de ordenação do mundo e ver passivamente os agentes sociais como reprodutores de uma lógica arbitrária, compreende as práticas culturais como um jogo de forças que reflete uma ordem social hierarquizada. Neste sentido, a desigual distribuição de capital econômico e cultural, que é própria da dinâmica da sociedade capitalista, permite a constituição de práticas e disposições culturais variadas e tipos específicos de interesse de grupos. Para compreender as diferenças e semelhanças das disposições culturais dos jovens, utilizaremos o conceito de habitus. Ou seja, as escolhas de carreira dos estudantes serão analisadas por meio de um conjunto de disposições que expressam as divisões derivadas da estrutura de distribuição das diferentes formas de capital.

Este instrumental analítico nos serve de apoio para criar três classes de cursos, os seletos, os intermediários e os populares. ${ }^{4} \mathrm{~A}$ intenção de classificar refere-se apenas a um esforço exploratório para compreender uma realidade heterogênea e complexa - em outras palavras, uma tentativa de síntese que nos permita uma leitura processual e relacional dos dados obtidos. Procedendo a tal classificação, poderemos identificar a composição e o volume dos recursos - capital econômico, capital social e capital cultural - dos alunos das unidades investigadas e as vantagens ou não que esses recursos Ihes conferem. Também nos permitirá visualizar as semelhanças e as proximidades sociais e acadêmicas dos alunos e seus cursos no espaço universitário.

Para dar encaminhamento à nossa proposta devemos, antes, porém, comentar e analisar as informações contidas em algumas tabelas.
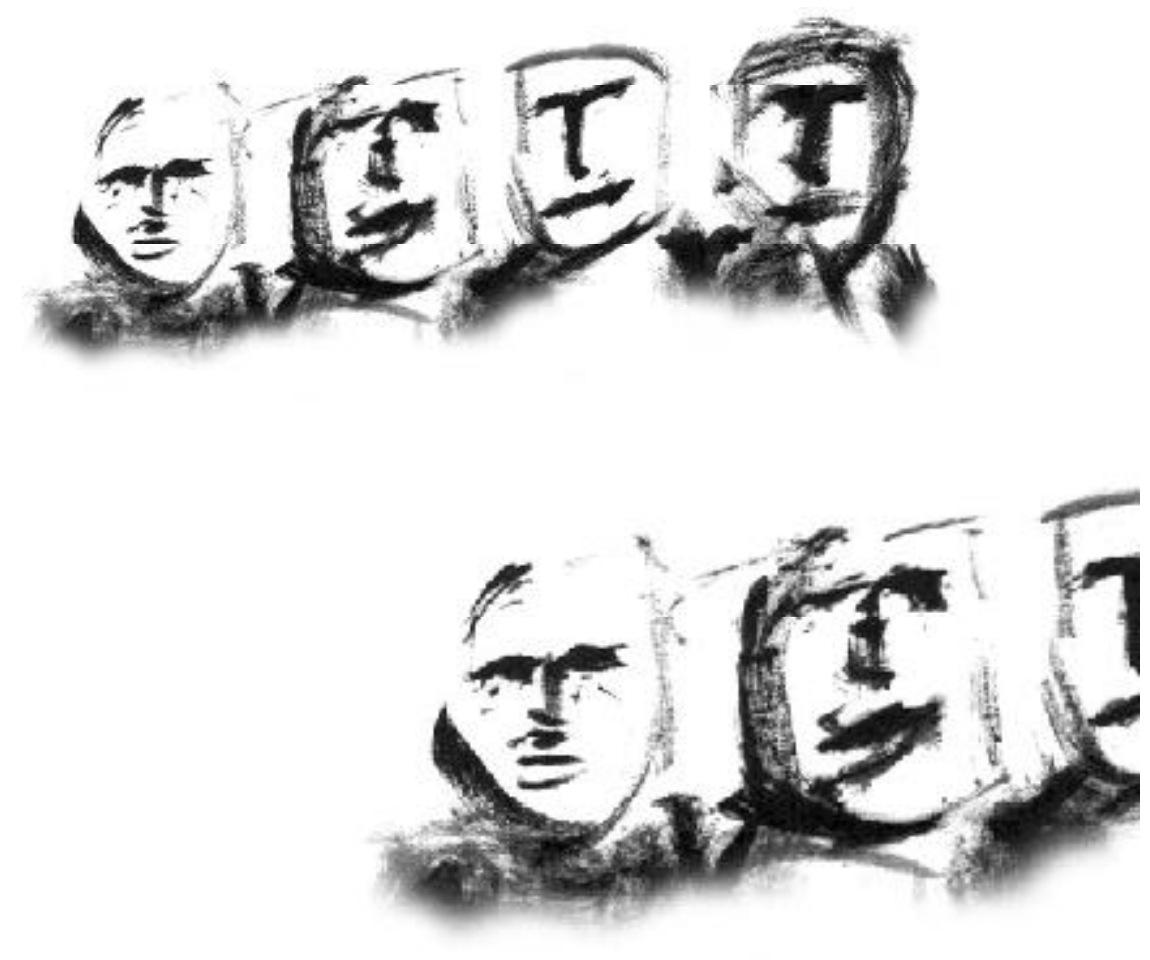

\section{Comentando algumas tabelas 5}

\section{Idade}

Em relação à idade observamos grosso modo que os cursos apresentam um público de alunos bastante jovem: na faixa de 17 a 24 anos encontram-se $71 \%$ dos alunos; de 25 a 30 anos, a porcentagem é bastante inferior, 18,6\%; com mais de 31 anos, apenas $9,2 \%$.

Não obstante, alguns cursos se destacam mais do que outros por se constituírem de uma população de bem pouca idade (Tabela 1). É o caso dos veteranos dos cursos que possuem mais de $80 \%$ de seus alunos na faixa de 17 a 24 anos, tais como Relações Públicas (92,9\%), Jornalismo $(84,2 \%)$, Direito $(81,4 \%)$, Publicidade $(84,4 \%)$, Psicologia $(80,5 \%)$. Por sua vez, os cursos com clientela mais madura, na faixa de 31 a mais de 40 anos, são os de Pedagogia $(49,8 \%)$, Biblioteconomia $(38,0 \%)$ e Contabilidade $(19,7 \%)$.

\footnotetext{
4 No artigo "Democratização do ensino superior", Aparecida Joly Gouveia (1968) faz a mesma classificação com alguns cursos oferecidos por três instituições de ensino superior (Universidade Mackenzie, USP e PUC-SP), segundo a origem social de seus estudantes. Para construir tal classificação, a autora se baseia nas diferenças de origem social dos alunos, sendo a ocupação do pai o principal critério classificatório. Nosso propósito, no entanto, é outro: faremos a classificação segundo diversos indicadores.

5 Nas tabelas, em cada item comentado, encontraremos informações sobre calouros e veteranos. Por calouros entendemos os alunos ingressados no momento da pesquisa (portanto, apenas os do primeiro ano) e por veteranos, aqueles matriculados a partir do segundo ano de curso.
} 
Tabela 1 - Distribuição dos estudantes de Humanidades da USP segundo curso, faixa etária e situação de ingresso - 1999 (em \%)

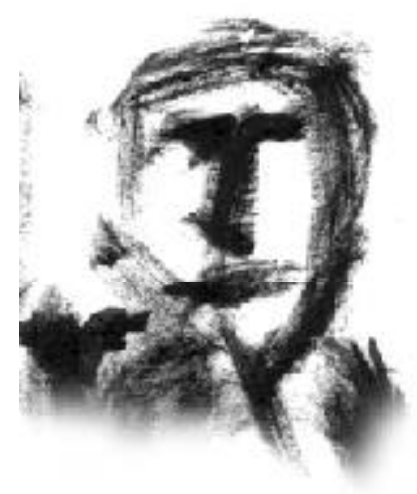

\begin{tabular}{|c|c|c|c|c|c|c|c|c|}
\hline \multirow[b]{2}{*}{$\begin{array}{l}\text { Situaçào de ingressol } \\
\text { Faixa etária (anos) }\end{array}$} & \multicolumn{4}{|c|}{ Calouros } & \multicolumn{4}{|c|}{ Veteranos } \\
\hline & $17-24$ & $25-30$ & $31-35$ & $\begin{array}{l}\text { Acima } \\
\text { de } 36\end{array}$ & $17-24$ & $25-30$ & $31-35$ & $\begin{array}{l}\text { Acima } \\
\text { de } 36\end{array}$ \\
\hline Administração & 95,7 & 1,8 & 0,6 & 1,2 & 64,9 & 27,4 & 5,4 & 0,9 \\
\hline Economia & 93,4 & 3,3 & 1,3 & 2,0 & 73.6 & 17,3 & 6,3 & 1.0 \\
\hline Contabilidade & 83,3 & 10,2 & 2,8 & 2,8 & 49,8 & 36,2 & 9,4 & 4,7 \\
\hline Direito & 83,4 & 8,0 & 3.9 & 3.6 & 81.4 & 10,6 & 3,9 & 3.4 \\
\hline Psicologia & 93,4 & 3,3 & 1,6 & 1,6 & 805 & 11,7 & 4,3 & 2.6 \\
\hline Asquitetura & 96.2 & 1.5 & 0,8 & 1.5 & 69.2 & 27.9 & 1,6 & 1,3 \\
\hline Pedagogia & 70,1 & 10,3 & 10,3 & 7,7 & 48.0 & 20,9 & 16.6 & 152 \\
\hline Jornalismo & 95,0 & 2,5 & 2.5 & 0.0 & 84,2 & 10,5 & 21 & 1,1 \\
\hline Editoraça & 92,3 & 0,0 & 0,0 & 0,0 & 51,6 & 38,7 & 3,2 & 3.2 \\
\hline Turismo & 100,0 & 0,0 & 0,0 & 0,0 & 76.0 & 18,0 & 20 & 0.0 \\
\hline Publicidade & 100,0 & 0,0 & 0,0 & 0,0 & 84.4 & 14.1 & 1,6 & 0.0 \\
\hline Biblioteconomia & 66.7 & 18,5 & 7,4 & 7.4 & 326 & 44,2 & 20,9 & 2.3 \\
\hline Artes Plásticas & & 0,0 & 0,0 & 0,0 & 86.0 & 21,3 & 8,5 & 2.1 \\
\hline Artes Cênicas & 77,3 & 4,5 & 13,6 & 0,0 & 73.8 & 26,2 & 0,0 & 0,0 \\
\hline Radio/TV & 93,3 & 6,7 & 0,0 & 0,0 & 888 & 25,0 & 0,0 & 0.0 \\
\hline Cinema & 83,3 & 0.0 & 0.0 & 0.0 & 71,9 & 18,8 & 9,4 & 0.0 \\
\hline Relaçóes Públicas & 92,6 & 3.7 & 3,7 & 0,0 & 929 & 4,8 & 24 & 0.0 \\
\hline Música & 90.5 & 4,8 & 0,0 & 0,0 & 780 & 15,9 & 4,9 & 1.2 \\
\hline
\end{tabular}

No que se refere aos calouros, a faixa etária de 17 a 24 anos concentra um número de alunos maior que o verificado entre os veteranos, ou seja, $89,3 \%$. Destacam-se novamente os cursos de Turismo (100\%), Publicidade (100\%), Jornalismo (95\%), Psicologia (93,4\%), Relações Públicas (92,6\%) e Música $(90,5 \%)$ por concentrarem os mais jovens - mais de $90 \%$ de seus alunos ainda não completaram 25 anos.

Todavia, vale ressaltar que observamos algumas variações interessantes. Os cursos de Direito e Relações Públicas, tanto entre os calouros como entre os veteranos, apresentam um porcentual de alunos semelhante na faixa etária de 17 a 24 anos, o que indica que são cursos que se destacam por se constituírem pela clientela mais jovem. Por outro lado, nessa faixa ainda, entre os estudantes de Contabilidade $(49,8 \%$ veteranos e $83,3 \%$ calouros), Biblioteconomia (32,6\% veteranos e $66,7 \%$ calouros) e Pedagogia ( $48 \%$ veteranos e $70,1 \%$ calouros), é interessante salientar que, entre os calouros, a clientela torna-se sensivelmente mais jovem se comparada à realidade dos veteranos.
Especificamente em relação aos alunos da Faculdade de Filosofia, Letras e Ciências Humanas (FFLCH) impõe-se uma avaliação à parte (Tabela 2). Observamos uma significativa diferença na distribuição porcentual nas faixas etárias, se comparada com a de outras unidades da Universidade de São Paulo (USP). Nesses cursos, os alunos se constituem de um público mais velho. Por exemplo, o curso de Filosofia conta com apenas $32,5 \%$ de alunos de até 24 anos, $29,4 \%$ na faixa de 25 a 30 anos e $36,2 \%$ com mais de 30 anos. O curso de Ciências Sociais é o que apresenta alunos mais jovens dentro da FFLCH: $60,8 \%$ possui no máximo 24 anos; $28 \%$, entre 25 a 30 anos; $10,3 \%$, mais de 30 anos. Ressaltamos, no entanto, que, entre os calouros, todos os cursos da FFLCH apresentam mais de $70 \%$ de seus alunos na faixa etária mais jovem, com exceção da Filosofia. Contudo, vale salientar que mesmo nesse curso, se compararmos a idade dos calouros e dos veteranos, observaremos um expressivo processo de rejuvenescimento do corpo discente. 
Tabela 2 - Distribuição dos estudantes da FFLCH/USP segundo curso, faixa etária e situação de ingresso - 1997 (em \%)

\begin{tabular}{|l|c|c|c|c|c|c|}
\hline \multirow{2}{*}{$\begin{array}{c}\text { Faixa Etária (anos)? } \\
\text { Situargato de Ingresso }\end{array}$} & \multicolumn{2}{|c|}{$17-24$} & \multicolumn{2}{c|}{$25-30$} & \multicolumn{2}{c|}{ Acima de 30} \\
\cline { 2 - 7 } & Calouros & Veteranos & Calouros & Veteranos & Calouros & Veteranos \\
\hline Ciéncias Sociais & 89,0 & 60,8 & 6,6 & 28,0 & 10,3 & 10,3 \\
\hline Filosofia & 62,4 & 32,5 & 16,2 & 29,4 & 21,4 & 36,2 \\
\hline Geografia & 75,1 & 43,0 & 15,0 & 33,2 & 8,1 & 21,6 \\
\hline História & 80,3 & 54,9 & 9,0 & 27,4 & 10,3 & 15,6 \\
\hline Letras & 71,5 & 0,5 & 12,9 & 31,3 & 13,9 & 21,7 \\
\hline
\end{tabular}

\section{Período}

Os cursos de Humanidades investigados (Tabela 3 ) oferecem períodos de funcionamento distintos: grande parte deles funciona nos períodos noturno e diurno (vespertino e matutino) e uma parcela pequena, porém significativa, oferece apenas o período integral - são os cursos de Cinema, Arquitetura, Psicologia e, parcialmente, Artes Cênicas, Artes Plásticas e Música.

Tabela 3 - Distribuição dos estudantes de Humanidades da USP segundo curso, período de matrícula e situação de ingresso - 1999 (em \%)

\begin{tabular}{|c|c|c|c|c|c|c|c|c|}
\hline \multirow{2}{*}{$\begin{array}{c}\text { Situaça de Ingressol } \\
\text { Perioda }\end{array}$} & \multicolumn{4}{|c|}{ Calouros } & \multicolumn{4}{|c|}{ Veteranos } \\
\hline & $11=-$ no & Wat.st ne & :ogral & $\operatorname{cesp}=-\mathrm{i} 10$ & oturne & Mazuj-a & ntegra: & cespolt 70 \\
\hline Administracąo & 49.7 & 48,5 & 1,2 & 0,6 & 58,6 & 40.6 & 0,9 & 0,0 \\
\hline Economia & 47,0 & 50,3 & 2,0 & 0.7 & 50,0 & 49.0 & 0,0 & 0.5 \\
\hline Contabilidade & 63.0 & 37. 0 & 0.0 & 0,0 & 60,9 & 382 & 0,0 & 0,4 \\
\hline Direito & 49,0 & 50,8 & 0,0 & 0.0 & 47.5 & 51.8 & 0.0 & 0,2 \\
\hline Psicologia & 1.6 & 4.9 & 91.8 & 0.0 & 0,9 & $4: 8$ & 0,9 & 0,4 \\
\hline Arcuitetura & 0.8 & 1.5 & 96.9 & 0,0 & 0,0 & 1,0 & 1,0 & 0,3 \\
\hline Pedagogia & 50,4 & 49,6 & 0,0 & 0,0 & 57,9 & 1,0 & 0,0 & 41.1 \\
\hline Jornalismo & 47.5 & 52,5 & 0,0 & 0.0 & 37,6 & 60.0 & 1,6 & 0,8 \\
\hline Eclitoraçăo & 7,7 & 92,3 & 0,0 & 0,0 & 0,0 & 93,5 & 3,2 & 3.2 \\
\hline Turismo & 100,0 & 0,0 & 0,0 & 0.0 & 98,0 & 20 & 0,0 & 0,0 \\
\hline Publicidade & 53.1 & 46.9 & 0.0 & 0.0 & 56,7 & $41: 4$ & 0,0 & 1.9 \\
\hline Eiblioteconomia & 48,1 & 48,1 & 0,0 & 3.7 & 48,8 & 46.5 & 0,0 & 0,0 \\
\hline Artes Plásticas & 0.0 & 0.0 & 0.0 & 0.0 & 0,0 & 148 & 72,3 & 12,8 \\
\hline Artes Cennicas & 0.0 & 22,7 & 72,7 & 0,0 & 0,0 & 2,4 & 92,9 & 4,8 \\
\hline Rádio/TV & 0,0 & 86.7 & 6,7 & 0.0 & 0,0 & 73.3 & 0,0 & 26,7 \\
\hline Cinema & 16,1 & 33,3 & 60,0 & 0,0 & 0,0 & 0,0 & 100,0 & 0,0 \\
\hline Relaçōes Públicas & 44,4 & 51,9 & 0,0 & 3.7 & 4,8 & 92.9 & 0,0 & 2,4 \\
\hline Música & 0.0 & 57.1 & 14.3 & 0,0 & 0,0 & 41,5 & 52,4 & 6,1 \\
\hline
\end{tabular}

Entre os veteranos, os cursos da Faculdade de Economia, Administração e Contabilidade (FEA), de Direito e alguns da Escola de Comunicações e Artes (ECA) - Publicidade, Jornalismo, Editoração, Relações Públicas, Rádio/TV e Música - são responsáveis por quase um terço das matrículas no período matutino. Oferecendo disciplinas no período vespertino destacam-se apenas os cursos de Pedagogia e Rádio/TV.

No total de cursos pesquisados, observamos uma procura maior dos veteranos pelo período noturno, 39,5\%. ${ }^{6}$ As unidades que apresentaram os maiores índices de matrículas no período noturno são: Turismo (98\%), Contabilidade $(60,9 \%)$, Administração $(58,6 \%)$, Pedagogia $(57,9 \%)$ e Publicidade $(56,7 \%)$. Os cursos de Economia, Direito e Biblioteconomia apresentam um número de matrículas equilibrado nos dois períodos oferecidos. Em relação aos calouros os dados são semelhantes.

No que se refere aos alunos da FFLCH (Tabela 4) - que oferece os dois períodos - , a maioria dá preferência ao período noturno, sobretudo os veteranos, em especial no curso de Filosofia, com o maior número de matrículas $(58,2 \%)$, talvez por atrair um número significativo de

\footnotetext{
6 A título de curiosidade: matutino $33,9 \%$, integral $21,5 \%$ e vespertino $4,7 \%$.
} 
alunos mais velhos e provavelmente com a responsabilidade de se auto-sustentar. Os cursos de Geografia (53,7\%), Ciências
Sociais (55\%), História (52,3\%) e Letras (54\%) apresentam índices expressivos de matrículas no período noturno.

Tabela 4 - Distribuição dos estudantes FFLCH/USP segundo curso, período de matrícula e situação de ingresso 1997 (em \%)

\begin{tabular}{|l|c|c|c|c|c|c|}
\hline \multirow{2}{*}{$\begin{array}{c}\text { Situaçăo de Ingressol } \\
\text { Periodo }\end{array}$} & \multicolumn{3}{|c|}{ Calouros } & \multicolumn{3}{c|}{ Veteranos } \\
\cline { 2 - 8 } Ciências Sociais & 0.0 & 47,5 & 47.5 & 2.4 & 40,9 & 55.0 \\
\hline Filosofía & 0,0 & 41.9 & 55,6 & 1,9 & 35,6 & 58,2 \\
\hline Geografia & 20.0 & 21,3 & 50.0 & 0.0 & 43,9 & 53.7 \\
\hline Historia & 1,3 & 49,8 & 47,5 & 0,2 & 45,4 & 52,3 \\
\hline Letras & 52,0 & 0,0 & 47,0 & 43,2 & 1,0 & 54,0 \\
\hline
\end{tabular}

\section{Conclusão do segundo grau}

Na questão há quanto tempo tinham concluído o ensino médio, observam-se alguns dados interessantes (Tabela 5). Tomando apenas os dados relativos aos calouros - eles podem apresentar tendências mais claras sobre o assunto - , verificamos que os cursos nos quais os alunos ingressaram com mais facilidade, ou seja, imediatamente após concluírem o ensino médio, são na maioria da ECA - Turismo (57,1\%), Publicidade (56,3\%), Jornalismo (55\%), Cinema (50\%), Direito
(46,6\%) e Editoração (46,2\%). Metade dos alunos de Arquitetura (50\%), Contabilidade $(50 \%)$, Administração $(49,1 \%)$ e Editoração $(53,8 \%)$ levou de um a dois anos para realizar os planos de ingresso no ensino superior. Os cursos formados por alunos que retardaram por mais de seis anos o ingresso na universidade são Biblioteconomia (33,3\%), Pedagogia $(26,4 \%)$, Artes Cênicas $(22,7 \%)$ e Contabilidade (18,6\%). É importante salientar que são cursos com um número expressivo de alunos mais maduros e casados, dois deles com maioria feminina. ${ }^{7}$

Tabela 5 - Distribuição dos estudantes de Humanidades da USP segundo curso, ano de conclusão ensino médio e situação de ingresso - 1999 (em \%)

\footnotetext{
Não possuímos essa informação sobre os alunos da FFLCH/USP
}

\begin{tabular}{|c|c|c|c|c|c|}
\hline \multirow{2}{*}{$\begin{array}{c}\text { Situaçso de Ingressol } \\
\text { Periodo (anos) }\end{array}$} & \multicolumn{5}{|c|}{ Calouros } \\
\hline & Mesmo ano & $1-2$ & $3-5$ & $6-10$ & Mais de 11 \\
\hline Administraçâo & 36,2 & 49.1 & 8,0 & 2,5 & 1.8 \\
\hline Economia & 38,4 & 45.7 & 9,3 & 4,0 & 2.6 \\
\hline Contabilidade & 17,6 & 50.0 & 13,0 & 13,0 & 56 \\
\hline Direito & 46,6 & 33,4 & 3,9 & 6,2 & 9,6 \\
\hline Psicologia & 27,9 & 45.9 & 16,4 & 3.3 & 3.3 \\
\hline Arquitetura & 36.2 & 50.0 & 6.2 & 1,5 & 2.3 \\
\hline Pedagogia & 21,4 & 29,9 & 14,5 & 8,5 & 17,9 \\
\hline Jomalismo & 55,0 & 35.0 & 0,0 & 5,0 & 2.5 \\
\hline Editoraçåo & 46.2 & 53,8 & 0,0 & 0,0 & 0,0 \\
\hline Turismo & 57,1 & 42.9 & 0,0 & 0,0 & 0.0 \\
\hline Publicidade & 56.3 & 31.3 & 9.4 & 3,1 & 0,0 \\
\hline Eblioteconomia & 7,4 & 29.6 & 25,9 & 11.1 & 22,2 \\
\hline Artes Plásticas & - & 0.0 & 0,0 & 0,0 & 0.0 \\
\hline Artes Cênicas & 40,9 & 27,3 & 9,1 & 9,1 & 13,6 \\
\hline Rádio/TV & 46,7 & 40.0 & 13,3 & 0,0 & 0.0 \\
\hline Cinema & 50,0 & 33,3 & 0,0 & 0,0 & 0,0 \\
\hline Releçóes Públicas & 37,0 & 37.0 & 18,5 & 0,0 & 3.7 \\
\hline Música & 38,1 & 42.9 & 9,5 & 9,5 & 0.0 \\
\hline
\end{tabular}




\section{Língua estrangeira}

Com a intenção de melhor avaliar a bagagem cultural dos alunos que ingressaram nos cursos de Humanidades da USP, achamos pertinente anexar a esse tópico de análise as informações sobre seu conhecimento de línguas estrangeiras. Considerar o volume e a composição do capital cultural adquirido pelos alunos dos diferentes cursos implica perguntar, entre outras coisas, qual o conhecimento que tinham de outras línguas, já que o domínio de um idioma é um dos quesitos mais importantes no atual mercado de trabalho. Entre os alunos investigados, $56,2 \%$ declarou falar fluentemente a língua inglesa. As demais línguas européias, como francês, alemão, italiano e espanhol, são também bem conhecidas por 19,8\% dos alunos (Tabela 6).

Tabela 6 - Distribuição dos estudantes de Humanidades da USP segundo curso, conhecimento de línguas e situação de ingresso - 1999 (em \%)

\begin{tabular}{|c|c|c|c|c|c|c|c|c|}
\hline \multirow{2}{*}{$\begin{array}{l}\text { Situaçào de Ingressol } \\
\text { Linguas }\end{array}$} & \multicolumn{4}{|c|}{ Calouros } & \multicolumn{4}{|c|}{ Veteranos } \\
\hline & Inglés & Europeias & Orientais & N/R & |nglés & Europêias & Orientais & N/R \\
\hline Administraçáo & 56,4 & 9,2 & $6 . \overline{7}$ & 35,6 & 62.9 & 19,1 & 5.4 & 29.7 \\
\hline Economia & 53.6 & 14,6 & 2,0 & 35,1 & 60,1 & 25,0 & 2,9 & 31,3 \\
\hline Contabilidada & 25,9 & 2.8 & 5,6 & 820 & 39.1 & 4,7 & 9,0 & 52.4 \\
\hline Direito & 61.9 & 13.7 & 2,3 & 30,3 & 6877 & 25,2 & 2.4 & 24.2 \\
\hline Psicologia & 39,3 & 8,2 & 3,3 & 49,2 & 50,2 & 15,2 & 1,3 & 36,8 \\
\hline Arquitetura & 54,6 & 10.0 & 1,5 & 36.2 & 52.1 & 21,6 & 3,6 & 33.4 \\
\hline Pedagogia & 28,2 & 6,0 & 0,0 & 63,2 & 28,5 & 15,2 & 3,3 & 53,0 \\
\hline Jomalismo & 65,0 & 12.5 & 2,5 & 250 & 68.4 & 28,4 & 2,1 & 20,0 \\
\hline Editoraçâo & 46,2 & 15,4 & 0.0 & 385 & 41,9 & 3,2 & 0,0 & 54,8 \\
\hline Turismo & 66,7 & 4,8 & 0,0 & 33,3 & 66,0 & 24,0 & 4,0 & 30,0 \\
\hline Publicidade & 68,8 & 9.4 & 0,0 & 28.1 & 71.9 & 15,6 & 0,0 & 21.9 \\
\hline Biblioteconomia & 29.6 & 11,1 & 0,0 & 51,9 & 20,9 & 11,6 & 0.0 & 65,1 \\
\hline Artes Plásticas & 0,0 & 0.0 & 0,0 & & 48.9 & 17,0 & 0,0 & 31.9 \\
\hline Artes Cênicas & 31,8 & 13.6 & 0,0 & 59.1 & 33.3 & 21,4 & 0,0 & 42.9 \\
\hline Radio/T & 60,0 & 13.3 & 0,0 & 20,0 & 65.6 & 6,3 & 0.0 & $25: 0$ \\
\hline Cinema & 83,3 & 0.0 & 0,0 & 16.7 & 75,0 & 21,9 & 0,0 & 21.9 \\
\hline Relaçỏes Públicas & 44,4 & 11.1 & 7.4 & 407 & 64.3 & 33,3 & 4.8 & 28.6 \\
\hline Música & 47,6 & 9,5 & 0,0 & 429 & 40,2 & 9,8 & 1.2 & 43,9 \\
\hline
\end{tabular}

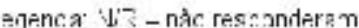

Se olharmos atentamente para as variações de cursos verificamos que os cursos de Cinema (75\%), Publicidade (71,9\%), Direito $(68,7 \%)$, Jornalismo $(68,4 \%)$, Turismo (66\%), Rádio/TV (65,6\%), Relações Públicas $(64,3 \%)$ e Administração (62,9\%) são os que concentram o maior número de alunos que falam fluentemente o inglês. Em relação às outras línguas européias, observamos que os cursos de Relações Públicas $(33,3 \%)$ Jornalismo $(28,4 \%)$ e Turismo (24\%) destacam-se novamente por apresentar um alto percentual de alunos com conhecimento dessas línguas, juntamente com os cursos de Economia (25\%) e Direito $(25,2 \%)$. É importante ressaltar, entretanto, que o maior número de não-respostas nessa questão (ou que não dominam outro idioma) se encontra nos cursos de Biblioteconomia $(65,1 \%)$, Pedagogia $(53 \%)$ e Contabilidade $(52,4 \%){ }^{8}$

\section{Instrução paterna}

É comum, nas análises socioeconômicas, a utilização do nível de instrução dos pais como indicador da origem social dos indivíduos. As barreiras impostas pela diferenciação dos níveis de ensino por muito tempo serviu como um referencial de hierarquização nas sociedades modernas. No entanto, a expansão da oferta de ensino para todos os níveis faz com que os limites entre os diferentes grupos sociais torne-se mais fluido e de difícil apreensão.

\footnotetext{
Contudo, salientamos que a vida universitária para alguns alunos contribuiu para o aprendizado de línguas. Essa é a conclusão a que chegamos ao comparar as respostas entre calouros e veteranos. Os alunos do curso de Relações Públicas foram os que mais aproveitaram a vida universitária para o aprendizado de línguas. A diferença de conhecimento dos idiomas (tanto do inglês como das línguas européias) entre calouros e veteranos desse curso é da ordem de $20 \%$. A mesma tendência, embora menos acentuada (média de 12\%), se verifica entre os veteranos dos cursos de Contabilidade e Psicologia. Na situação inversa, ou seja, onde se encontra maior número de calouros com conhecimento de línguas estrangeiras, estão os cursos de Cinema Editoração e Arquitetura.
} 
Dessa forma, embora saibamos que o tipo e os anos de escolaridade ainda constituem importantes elementos de distinção social, sabemos também que não podem ser vistos separadamente dos demais elementos que configuram o perfil sociocultural dos grupos. Nossa intenção é elaborar uma classificação que dê conta das particularidades e diferenças do capital cultural existente entre os alunos dos diversos cursos investigados. Para uma investigação mais apurada, iremos analisar essas informações agregando os porcentuais do grupo de educação rudimentar e fundamental, denominando-as como educação básica; o grupo de ensino médio como educação média; e o de ensino superior e pós como educação distintiva.

Em relação ao grau de instrução dos pais dos veteranos, observamos que mais da metade $(65,6 \%)$ possui instrução superior com pós-graduação. No entanto, devemos considerar as informações com mais cautela, verificando a variação por curso (Tabelas 7 e 8). Fica evidente, nesse quesito, uma acentuada diferença entre os cursos oferecidos.

Tabela 7 - Distribuição dos estudantes de Humanidades da USP segundo curso, instrução paterna e situação de ingresso - 1999 (em \%)

\begin{tabular}{|c|c|c|c|c|c|c|}
\hline \multirow{2}{*}{$\begin{array}{c}\text { Situaçäo de Ingressol } \\
\text { Instruçấo }\end{array}$} & \multicolumn{3}{|c|}{ Calouros } & \multicolumn{3}{|c|}{ Veteranos } \\
\hline & $\begin{array}{c}\text { Educacăo } \\
\text { Búsica }\end{array}$ & $\begin{array}{l}\text { Educacáo } \\
\text { Módia }\end{array}$ & $\begin{array}{l}\text { Educaçăo } \\
\text { Distintiva }\end{array}$ & $\begin{array}{c}\text { Educaçăo } \\
\text { Básica }\end{array}$ & $\begin{array}{c}\text { Educacảo } \\
\text { Media }\end{array}$ & $\begin{array}{l}\text { Educacâo } \\
\text { Distintiva }\end{array}$ \\
\hline Administraçâo & 6,7 & 18,6 & 76.7 & 18,3 & 16,6 & 65.1 \\
\hline Economia & 11.9 & 17.9 & 69.5 & 121 & 20,2 & 67,2 \\
\hline Contabiliciade & 34,3 & 19,4 & 45,4 & 29,6 & 23,8 & 44.7 \\
\hline Direito & 9,3 & 15,3 & 74,6 & 9,4 & 15,1 & 75,1 \\
\hline Psicologia & 11,4 & 18,0 & 70.6 & 10,0 & 16,9 & 72,7 \\
\hline Arquitctura & 6,2 & 16,4 & 76,8 & 9,8 & 16.7 & 74,2 \\
\hline Pedagogia & 36,8 & 15,4 & 46,1 & 38,5 & 20,9 & 39.3 \\
\hline Jornalisme & 10,0 & 20,0 & 70,0 & 7,4 & 25,3 & 65,2 \\
\hline Editoraçă & 15,4 & 7,7 & 769 & 6,4 & 22,6 & 71,0 \\
\hline Turismó & 9,5 & 19,0 & 71,5 & 8,0 & 24,0 & 66.0 \\
\hline Publicidade & 9,4 & 15,6 & 750 & 9,4 & 26.6 & 64,0 \\
\hline Eiblioteconomia & 55.5 & 25,9 & 7.5 & 48.9 & 30.2 & 18.6 \\
\hline Artes Plásticas & 0,0 & 0,0 & 0.0 & 19,1 & 21,3 & 59,6 \\
\hline Artes Cénicas & 22,7 & 18,2 & 59,1 & 11.9 & 7,1 & 81,0 \\
\hline Rádio/TV & 6,7 & 20,0 & 73.3 & 15,6 & 28.1 & 56.3 \\
\hline Cinema & 16,7 & 16,7 & 66.5 & 9,4 & 12,5 & 68,7 \\
\hline Relaçóes Públicas & 14,8 & 29,6 & 55.6 & 11,8 & 16.7 & 71.4 \\
\hline Música & 4,8 & 14,3 & 80.9 & 13,4 & 12,2 & 72,0 \\
\hline
\end{tabular}

Tabela 8 - Distribuição dos estudantes da FFLCH/USP segundo curso, instrução paterna e situação de ingresso - 1999 (em \%)

\begin{tabular}{|c|c|c|c|c|c|c|}
\hline \multirow[b]{2}{*}{$\begin{array}{l}\text { Situaçăo de ingresso/ } \\
\text { Instrução }\end{array}$} & \multicolumn{3}{|c|}{ Calouros } & \multicolumn{3}{|c|}{ Veteranos } \\
\hline & $\begin{array}{c}\text { Educaçâo } \\
\text { Bèsica }\end{array}$ & $\begin{array}{l}\text { Educa ção } \\
\text { Mádia }\end{array}$ & $\begin{array}{l}\text { Educaçấo } \\
\text { Dislintrovo }\end{array}$ & $\begin{array}{c}\text { Educaçấo } \\
\text { Básica }\end{array}$ & $\begin{array}{c}\text { Educação } \\
\text { Média }\end{array}$ & $\begin{array}{l}\text { Educaçâo } \\
\text { Distintiva }\end{array}$ \\
\hline Ciências Sociais & 19,4 & 16,6 & 60,2 & 38,0 & 18,8 & 40,0 \\
\hline Filosofia & 25.4 & 22.2 & 50,5 & 43.3 & 21,7 & 31.6 \\
\hline Geogralia & 33.7 & 23.1 & 40,6 & 50.4 & 25,3 & 18.3 \\
\hline História & 21.5 & 21.1 & 54,8 & 39.2 & 19.4 & 374 \\
\hline Letras & 32,4 & 20,8 & 42,2 & 42,2 & 25,1 & 29,5 \\
\hline
\end{tabular}

Vejamos. Entre os veteranos, os cursos onde se destacam pais com nível de educação distintiva são os de Artes Cênicas $(81 \%)$, Direito $(75,2 \%)$, Arquitetura $(74,2 \%)$, Psicologia (72,7\%), Música (72\%),
Relações Públicas (71,4\%), Editoração (71\%) e Cinema (68,7\%). Por outro lado, os cursos de Geografia $(50,4 \%)$, Biblioteconomia (48,9\%), Filosofia (43,3\%), Letras (42,2\%), Pedagogia (38,5\%), Ciências Sociais (38\%) e 
Contabilidade $(29,6 \%)$ se destacam por concentrar o maior número de pais agrupados no nível educação básica.

Quanto aos calouros, observamos a mesma tendência. Os cursos de Música (80,9\%), Editoração (76,9\%), Arquitetura (76,9\%), Administração $(76,7 \%)$, Publicidade $(75 \%)$, Direito $(74,6 \%)$, Rádio/TV (73,3\%), Turismo (71,5\%), Psicologia $(70,6 \%)$, Jornalismo $(70 \%)$ e Economia $(69,5 \%)$ são os que apresentam um número elevado de pais de alunos com capital cultural distintivo. Por outro lado, os cursos de Biblioteconomia (55,5\%), Pedagogia $(36,8 \%)$, Contabilidade $(34,3 \%)$, Geografia $(33,7 \%)$ e Letras $(32,4 \%)$ concentram o maior número de pais com educação básica. Observamos que quase um quarto dos alunos dos cursos de Filosofia e História possui pais nessa mesma condição.

Se compararmos a instrução dos pais dos alunos calouros e veteranos, observamos alguns dados interessantes. Os alunos que mantêm igual volume de capital cultural tanto entre calouros como entre os veteranos se encontram nos cursos de Economia, Contabilidade, Direito, Psicologia, Arquitetura e Cinema.

\section{Instrução materna}

A instrução materna poderá nos ajudar a completar o quadro de informações sobre o capital cultural herdado dos alunos. Entre os veteranos, observamos que $52,3 \%$ das mães dos alunos se encontram no grupo educação distintiva. Todavia, devemos analisar essa informação a partir das variações por curso (Tabelas 9 e 10). Em alguns, observamos que a tendência verificada na instrução do pai se repete, ou seja, cursos como o de Relações Públicas (64,3\%), Artes Cênicas $(66,7 \%)$, Cinema (59,3\%), Direito $(61,9 \%)$, Arquitetura $(60,2 \%)$ e Psicologia (58\%), ${ }^{9}$ são os que apresentam o maior número de mães com instrução distintiva. Assim sendo, podemos concluir que são esses cursos que detêm um significativo porcentual de alunos com capital cultural familiar diferenciado, pois pais e mães possuem alto volume de capital cultural institucional. Em condição inversa, os cursos que apresentam alunos com menor nível de capital cultural institucional, ou seja, alta porcentagem de pais e mães agrupados no nível de educação básica, são Biblioteconomia (60,4\%), Geografia $(60,1 \%)$, Letras $(51,5 \%)$, Filosofia $(51,1 \%)$, História $(47,3 \%)$, Pedagogia $(43,1 \%)$ e Contabilidade $(39,9 \%)$.

Tabela 9 - Distribuição dos estudantes de Humanidades da USP segundo curso, instrução materna e situação de ingresso - 1999 (em \%)

\begin{tabular}{|c|c|c|c|c|c|c|}
\hline \multirow{2}{*}{$\begin{array}{c}\text { Situaçăo de Ingressol } \\
\text { Instruçâa }\end{array}$} & \multicolumn{3}{|c|}{ Calcuros } & \multicolumn{3}{|c|}{ Veteranos } \\
\hline & $\begin{array}{c}\text { Educação } \\
\text { Basica }\end{array}$ & $\begin{array}{c}\text { Educaçâo } \\
\text { Mediá }\end{array}$ & $\begin{array}{l}\text { Educaçào } \\
\text { Distintiva }\end{array}$ & $\begin{array}{l}\text { Educaçâo } \\
\text { Básica }\end{array}$ & $\begin{array}{l}\text { Educaçăo } \\
\text { Medfia }\end{array}$ & $\begin{array}{l}\text { Educaçâo } \\
\text { Distintiva }\end{array}$ \\
\hline Administraçâo & 11.6 & 23,9 & $B 3,9$ & 20,0 & 28,8 & 51.1 \\
\hline Economia & 8.0 & 29,8 & 61,5 & 16,3 & 29,3 & 53.9 \\
\hline Contabilidade & 35,2 & 34.3 & 29,6 & 39.9 & 31,8 & 25,3 \\
\hline Direito & 12,2 & 20,7 & 66,1 & 12,0 & 25,7 & 61,9 \\
\hline Psicologia & 9.8 & 21,3 & 68,9 & 14,7 & 26,9 & 58.0 \\
\hline Arquitetura & 11,5 & 23,8 & 34,7 & 14,8 & 24,3 & 60,2 \\
\hline Pedagugia & 40.1 & 31,6 & 26,6 & 43,1 & 29,1 & 26.1 \\
\hline Jornalismo & 12,5 & 22,5 & 65,0 & 13.7 & 25,2 & 59,0 \\
\hline Editoracăo & 0.0 & 23,0 & 77,0 & 19,3 & 35,5 & 45.2 \\
\hline Turismo & 9,5 & 23,8 & 66,7 & 12,0 & 32,0 & 54,0 \\
\hline Publicidade & 12.5 & 21,9 & 85,6 & 9,4 & 31,3 & 59.3 \\
\hline Biblioteconomia & $4 \mathrm{~B}, 1$ & 29,6 & 14,9 & 60.4 & 16,3 & 18,6 \\
\hline Artes Plásticas & 0.0 & 0,0 & 0,0 & 19.1 & 29,8 & 51.0 \\
\hline Artes Cenicas & 22,7 & 22,7 & 54,6 & 11,9 & 21,4 & 66,7 \\
\hline Rádio/TV & 26.7 & 20,0 & 53,3 & 12,5 & 34,4 & 53.1 \\
\hline Cinema & 0.0 & 33,3 & 66,7 & 3,1 & 31,3 & 59.3 \\
\hline Relaçōes Públicas & 33.3 & 25,9 & 40,8 & 11.9 & 23,8 & 64.3 \\
\hline Música & 4.8 & 19,0 & 76,2 & 19.5 & 23,2 & 56.1 \\
\hline
\end{tabular}

9 Os cursos, ora citados, são aqueles em que mais de $70 \%$ dos pais têm nível de instrução distintiva. 
Tabela 10 - Distribuição dos estudantes da FFLCH segundo curso, instrução materna e situação de ingresso - 1997 (em \%)

\begin{tabular}{|c|c|c|c|c|c|c|}
\hline \multirow{2}{*}{$\begin{array}{c}\text { Situação de Ingressol } \\
\text { Instruçào }\end{array}$} & \multicolumn{3}{|c|}{ Calouros } & \multicolumn{3}{|c|}{ Veteranos } \\
\hline & $\begin{array}{c}\text { Educaçâo } \\
\text { Bèsica }\end{array}$ & $\begin{array}{l}\text { Educação } \\
\text { Mádia }\end{array}$ & $\begin{array}{l}\text { Educaçâo } \\
\text { Dislintiove }\end{array}$ & $\begin{array}{c}\text { Educação } \\
\text { Básica }\end{array}$ & $\begin{array}{c}\text { Educaçào } \\
\text { Média }\end{array}$ & $\begin{array}{l}\text { Educacâa } \\
\text { Distintiva }\end{array}$ \\
\hline Ciências Sociais & 24,3 & 28,7 & 46,4 & 42,5 & 27,4 & 28,6 \\
\hline Filosofia & 39.4 & 22.2 & 36,7 & 51.1 & 22,9 & 24.1 \\
\hline Geografia & 41.3 & 28.1 & 29,4 & 60.1 & 21,8 & 16.4 \\
\hline História & 28.2 & 29.1 & 40,8 & 47.3 & 26.6 & 24.2 \\
\hline Letras & 42,5 & 28,5 & 27,0 & 51,5 & 28,7 & 178 \\
\hline
\end{tabular}

No que se refere aos calouros, observamos que a tendência é semelhante à verificada entre os veteranos em apenas alguns cursos. Nesse sentido, os alunos de Biblioteconomia $(48,1 \%)$, Letras $(42,5 \%)$, Geografia (41,3\%), Pedagogia $(40,1 \%)$, Filosofia $(39,4 \%)$ e Contabilidade $(35,2 \%)$ são os responsáveis pela manutenção da homogeneidade de recursos culturais, apresentando novamente um número significativo de mães com menor volume de capital cultural. Por outro lado, os cursos de Música $(76,2 \%)$, Editoração (77\%), Psicologia (68,9\%), Cinema (66,7\%), Turismo (66,7\%), Direito $(66,1 \%)$ e Publicidade $(65,6 \%)$ destacam-se por concentrar o maior número de mães com formação superior, confirmando a igualdade no alto volume de recursos culturais entre calouros e veteranos desses cursos.

\section{Renda familiar}

$\mathrm{Na}$ tentativa de detectar as diferenças ou semelhanças entre os alunos de Humanidades da USP, optamos por analisar separadamente as questões sobre renda e ocupação paterna. A fim de tornar as informações mais esclarecedoras, agrupamos algumas faixas. Observamos que nas faixas de renda mais altas (de $\mathrm{R} \$ 5,2$ mil a $\mathrm{R} \$ 7,8$ mil e mais de $\mathrm{R} \$ 7,8$ mil) concentram-se $12,7 \%$ dos alunos e $15,3 \%$ respectivamente - ao todo, $28 \%$. Nas faixas intermediárias (de $\mathrm{R} \$ 2,6$ mil a $\mathrm{R} \$ 5,2$ mil) encontramos $26,9 \%$; e nas faixas de renda mais baixas (de $R \$ 200$ a $\mathrm{R} \$ 2,6 \mathrm{mil}), 24,4 \%$.

Grosso modo, podemos afirmar que a renda familiar dos estudantes investigados apresenta uma certa proporcionalidade. Não obstante, seria interessante observar a distribuição das faixas de renda pelos cursos (Tabela 11). Vejamos. Entre os veteranos, os cursos que se destacam por estar melhor representados nas faixas de renda mais altas são Direito (37\%), Administração $(35,1 \%)$, Economia $(30,4 \%)$, Arquitetura $(31,9 \%)$, Editoração (29\%), Relações Públicas (28,5\%), Publicidade $(28 \%)$ e Cinema $(28,1 \%)$. Os mais constantes nas faixas de renda mais baixas são Biblioteconomia $(51,2 \%)$, Pedagogia (40,5\%), Artes Plásticas (40,5\%). Nas faixas intermediárias salientam-se: Turismo (36\%), Relações Públicas (31\%) e Contabilidade (32\%).

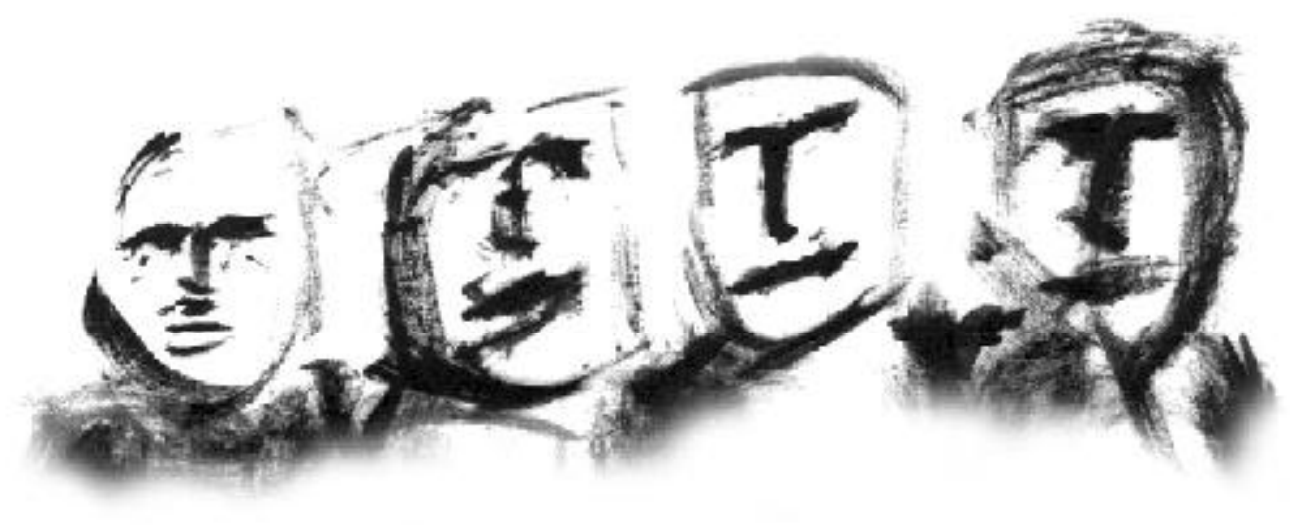


Tabela 11 - Distribuição dos estudantes de Humanidades da USP segundo curso, renda familiar e situação de ingresso - 1999 (em \%)

\begin{tabular}{|c|c|c|c|c|c|c|c|c|c|c|}
\hline \multirow[b]{2}{*}{$\begin{array}{c}\text { Situaçào de Ingressol } \\
\text { Renda (R\$) }\end{array}$} & \multicolumn{4}{|c|}{ Calouros } & \multirow[b]{2}{*}{ Oultost } & \multicolumn{4}{|c|}{ Veteranos } & \multirow[b]{2}{*}{ Outros' } \\
\hline & $\begin{array}{c}\text { Menos } \\
200\end{array}$ & $\begin{array}{l}200- \\
2.600\end{array}$ & $\begin{array}{l}2.600- \\
5.200\end{array}$ & $\begin{array}{l}\text { Acima } \\
5.200\end{array}$ & & $\begin{array}{c}\text { Menos } \\
200\end{array}$ & $\begin{array}{l}200- \\
2.600\end{array}$ & $\begin{array}{l}2.600- \\
5.200\end{array}$ & $\begin{array}{l}\text { Acima } \\
5.200\end{array}$ & \\
\hline Administraçâo & 0,0 & 21,6 & 22,1 & 35,0 & 21,3 & 0.0 & $22 \theta$ & 26,3 & 35,1 & 15,7 \\
\hline Economia & 0,0 & 22,4 & 23.2 & 35.9 & 18,5 & 0,0 & 21.6 & 29,3 & 30.4 & 18,7 \\
\hline Contabilidado & 0,0 & 39,7 & 26,9 & 9,2 & 24,2 & 0,4 & 31,4 & 32,2 & 12,8 & 23.2 \\
\hline Direito & 0,3 & 20.4 & 26,7 & 30,8 & 21.8 & 0.1 & 15,4 & 27.4 & 37,0 & 20,1 \\
\hline Psicologia & 0,0 & 34,4 & 18,0 & 26,3 & 21,3 & 0,4 & 25,2 & 25,1 & 24,2 & 25.1 \\
\hline Arquitetura & 0.8 & 20.7 & 27,7 & 30,8 & 20.0 & 0,3 & 25,3 & 21,6 & 31,9 & 20.9 \\
\hline Pedagogia & 0,0 & 48,7 & 24,8 & 17,1 & 9,4 & 0,3 & 40,5 & 27,5 & 11,5 & 20.2 \\
\hline Jornalismo & 0,0 & 30,0 & 27,5 & 22,5 & 20.0 & 0,0 & 23,3 & 27.4 & 26,2 & 23.1 \\
\hline Ecitoraçăo & 0,0 & 23,0 & 38,5 & 0,0 & 38,5 & 0,0 & 22,6 & 22,6 & 29,0 & 25.8 \\
\hline Turislrno & 0,0 & 28,4 & 38,1 & 23,9 & 9.6 & 0,0 & 24,0 & 36,0 & 24,0 & 16,0 \\
\hline Publicidada & 0,0 & 18,7 & 40,6 & 15,7 & 25,0 & 0,0 & 26,6 & 31,3 & 28,0 & 14.1 \\
\hline Biblioteconomia & 3,7 & 62,9 & 14,8 & 0,0 & 18.6 & 0,0 & 51,2 & 23,3 & 4,6 & 20.9 \\
\hline Artes Plasticas & 0,0 & 0,0 & 0,0 & 0,0 & 0,0 & 2,1 & 40,5 & 27,7 & 14,8 & 14.9 \\
\hline Altes Cênicas & 0.0 & 40,9 & 227 & 18,2 & 18.2 & 0.0 & 35,7 & 28,6 & 21,4 & 14,3 \\
\hline RádiofTV & 0,0 & 40,0 & 13,3 & 26,7 & 20,0 & 0,0 & 34,4 & 21,9 & 15,5 & 28.2 \\
\hline Cinema & 0.0 & 16.7 & 33,3 & 16,7 & 33.3 & 0,0 & 25,0 & 28.1 & 28,1 & 18.8 \\
\hline Relaçōes Públicas & 0,0 & 37,1 & 18,5 & 222 & 22,2 & 0,0 & 26,2 & 31,0 & 28,5 & 14,3 \\
\hline Música & & 38,1 & 42,9 & 9,6 & 9,4 & 0,0 & 25,6 & 17,1 & 14,7 & 42.6 \\
\hline
\end{tabular}

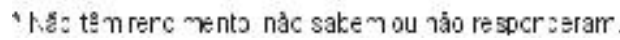

Em relação aos calouros, verificamos que nas faixas de renda mais altas encontram-se $27,1 \%$ dos alunos $(14,1 \%, R \$ 5,2$ mil a $R \$ 7,8$ mil; $13,0 \%$, mais de $R \$ 7,8$ mil); na faixa intermediária ( $R \$ 2,6$ mil a $\mathrm{R} \$ 5,2 \mathrm{mil}), 25,7 \%$; nas faixas mais baixas (de $\mathrm{R} \$ 200$ a $\mathrm{R} \$ 2,6 \mathrm{mil}$ ), $26,2 \%$. Verificamos algumas variações entre os cursos: os alunos com volume maior de renda estão em Economia (35,9\%), Administração (35\%), Direito $(30,8 \%)$ e Arquitetura $(30,8 \%)$; os de renda familiar mais baixa encontram-se nos cursos de Biblioteconomia (62,9\%), Pedagogia (48,7\%), Artes Cênicas (40,9\%), Rádio/TV (40\%), Contabilidade $(39,7 \%)$, Música $(38,1 \%)$ e
Relações Públicas $(37,1 \%)$. Nas faixas intermediárias, concentram-se os alunos dos cursos de Música (42,9\%), Editoração $(38,5 \%)$ e Turismo $(38,1 \%)$.

Quanto aos cursos da FFLCH, verificamos um número significativo de famílias com um volume baixo de renda (Tabela 12). $\mathrm{Na}$ faixa de renda de até $\mathrm{R} \$ 2$ mil, encontram-se as famílias dos alunos dos cursos de Geografia (59,9\%), Letras (56,8\%), Filosofia $(54,1 \%)$, História $(52,1 \%)$ e Ciências Sociais $(41,4 \%)$. Comparando veteranos e calouros, observamos que os calouros dos cursos dessa unidade têm seu volume de renda aumentado se comparado ao de seus colegas.

Tabela 12 - Distribuição dos estudantes da FFLCH/USP segundo curso, renda familiar e situação de ingresso - 1999 (em \%)

\begin{tabular}{|c|c|c|c|c|c|c|c|c|}
\hline \multirow[b]{2}{*}{$\begin{array}{c}\text { Situaça de lngressol } \\
\text { Renda (RS) }\end{array}$} & \multicolumn{4}{|c|}{ Calcuras } & \multicolumn{4}{|c|}{ Veteranos } \\
\hline & $\begin{array}{l}\text { Menos } \\
\text { ds } 1.000\end{array}$ & $\begin{array}{c}1.000 \mathrm{a} \\
2.000\end{array}$ & $\begin{array}{c}2.001 \mathrm{a} \\
5.000\end{array}$ & $\begin{array}{c}\text { Mais de } \\
5.000\end{array}$ & $\begin{array}{l}\text { Menos } \\
\text { de } 1.000\end{array}$ & $\begin{array}{l}1.000 \mathrm{a} \\
2.000\end{array}$ & $\begin{array}{c}2.001 \mathrm{a} \\
5.000\end{array}$ & $\begin{array}{l}\text { Mais de } \\
5.000\end{array}$ \\
\hline Ciências Sociais & 7.7 & 26.5 & 34,8 & $21: 0$ & 16,7 & 24.7 & 40,6 & 13,3 \\
\hline Filosofia & 13,7 & 34.2 & 29,9 & 18.9 & 30,6 & 30,6 & 31,9 & 11,8 \\
\hline Geografia & 19,4 & 36.3 & 33,1 & 10.6 & 37,0 & 37,0 & 29,4 & 5,6 \\
\hline História & 17,5 & 28,9 & 30,9 & 17,9 & 30,0 & 30,0 & 30,5 & 6,6 \\
\hline Letras & 19,5 & 33.3 & 33,3 & 10.2 & 39,0 & 39,0 & 31,9 & 7,8 \\
\hline
\end{tabular}




\section{Ocupação paterna}

No que se refere à ocupação paterna, a fim de apreender a variedade de funções no trabalho, o status e o nível de instrução necessário para seu desempenho, criamos inicialmente algumas categorias ocupacionais - Profissional Liberal (PL), Comerciante/Autônomo (C/A), Diretor/Presidente/ Pecuarista/Gerente (D/P/P/G), Profissional de Nível Superior (PNS), Profissional de Nível Médio (PNM), Profissional de Nível Básico (PNB) - ou seja, Profissional Doméstico sem Qualificação (PD), Profissional de Baixa Qualificação (PBQ) e Profissional com Alguma Qualificado (PAQ) - e a categoria Outros. É importante notar que, também nesse item, mantém-se a tendência à heterogeneidade verificada entre os cursos (Tabela 13). Observamos que as ocupações melhor remuneradas e conceituadas socialmente - Diretor/Presidente/ Pecuarista/Gerente (D/P/P/G), Profissional Liberal (PL) e Profissional de Nível Superior (PNS) - são desempenhadas, majoritariamente, pelos pais dos alunos dos cursos de Editoração (16,1\%/25,8\%/22,6\%), Relações Públicas (14,3\%/16,7\%/19,0\%), Psicologia (11,7\%/33,8\%/22,5\%), Administração $(12,0 \% / 19,1 \% / 22,6 \%)$ e Direito $(10,9 \% / 33,7 \% / 16,9 \%)$, respectivamente.

Tabela 13 - Distribuição dos estudantes de Humanidades - veteranos - da USP segundo curso e ocupação paterna - 1997-1999 (em \%)*

\begin{tabular}{|c|c|c|c|c|c|c|c|c|c|c|c|}
\hline Ocupaçào & DL & $P L$ & CIA & $\mathrm{D} / \mathrm{P} / \mathrm{P} / \mathrm{G}$ & PNS & Outros & PD & PBQ & PNM & PAQ & NR \\
\hline Actministraçăo & 0,0 & 19,1 & 16,3 & 12,0 & 22,6 & 3,7 & 3,7 & 4,0 & 13,4 & 6,0 & 0,0 \\
\hline Economia & 0,0 & 28,8 & 11,5 & 7.2 & 24,0 & & 4,8 & & 13,5 & & 0,0 \\
\hline Contabilidade & 0,0 & 14.2 & 16.7 & 3,4 & 19,7 & 4.7 & 6.4 & 8.6 & 9,4 & 16,7 & 0.4 \\
\hline Direito & 0,0 & 33,7 & 9,5 & 10.9 & 16.9 & 1,7 & 2,3 & 3,7 & 20,9 & 5,1 & 0,2 \\
\hline Psicologia & 0,0 & 33.8 & 6.5 & 11.7 & 22,5 & 1,3 & 1,7 & 5.2 & 16.0 & 5,2 & 0.0 \\
\hline Arquitetura & 0,0 & 34.1 & 8.5 & 9,8 & 18,0 & 2.3 & 3.9 & 3.6 & 16,4 & 4,3 & 0.0 \\
\hline Pedagogia & 0,3 & 149 & 14,6 & 5,6 & 15,2 & 4,3 & 10,3 & $\vartheta, 6$ & 12,6 & 11.9 & 0,7 \\
\hline Jornalismo & 0,0 & 23.2 & 6.3 & 13,7 & 21,1 & 1.1 & 3.2 & 9.5 & 23,2 & 4,2 & 0.0 \\
\hline Ecitoraçåa & 0,0 & 25,8 & 3,2 & 16,1 & 22,6 & 3,2 & 3,2 & 6.5 & 16,1 & 9,7 & 0,0 \\
\hline Turismo & 0,0 & 220 & 200 & 8,0 & 24,0 & 0.0 & 0.0 & 8.0 & 18,0 & 2,0 & 0.0 \\
\hline Publicidade & 0,0 & 25,0 & 7,8 & 6,3 & 23,4 & 1,6 & 0,0 & 3,1 & 21,9 & 10,9 & 0,0 \\
\hline Biblioteconomia & 0,0 & 4,7 & 9.3 & 4.7 & 23,3 & 11,6 & 18.6 & 7,0 & 14,0 & 16,3 & 0.0 \\
\hline Artes Plasticas & 0,0 & 10,6 & 10,6 & 10,6 & 25,5 & 0,0 & 6,4 & 6,4 & 25,5 & 8,5 & 0,0 \\
\hline Artes Cênicas & 0,0 & 26.2 & 7.1 & 7.1 & 26,2 & 2.4 & 24 & 2.4 & 23,8 & 4.8 & 0.0 \\
\hline Ràdia/TV & 3,1 & 31.3 & 6.3 & 6,3 & 18,8 & 0.0 & 9.4 & 9.4 & 15,6 & 0,0 & 3.1 \\
\hline Cinema & 0,0 & 45,9 & 3,1 & 6.3 & 9,4 & 3,1 & 0,0 & 9,4 & 9.4 & 12,5 & 0,0 \\
\hline Relacóes Públicas & 0,0 & 16.7 & 14.3 & 14,3 & 19,0 & 2.4 & 0.0 & 48 & 21,4 & 7,1 & 0.0 \\
\hline Música & 0.0 & 25.6 & 8.5 & 8,5 & 23.2 & 1.2 & 6.1 & 4.9 & 14.6 & 7,3 & 0.0 \\
\hline & PNB & & & - & PNS & - & - & - & PNM & - & Outros' \\
\hline Ciências Sociais & 25,4 & & & - & 25,4 & - & - & - & 15,5 & - & 33.7 \\
\hline Filosofia & 16,3 & & & - & 33. & - & - & - & 12,0 & - & 38.2 \\
\hline Geografia & 16,8 & & & - & 20.5 & - & - & - & 26.6 & - & 36,0 \\
\hline História & 23,2 & & & - & 32,9 & - & - & - & 16.7 & - & $27: 2$ \\
\hline Letras & 32,7 & & & - & 27,5 & - & - & - & 20,5 & - & 19.3 \\
\hline
\end{tabular}

* Os dados referentes aos cursos da FFLCH foram coletados em 1997 e os dados dos outros cursos foram coletados em 1999. A pesquisa de 1987 classificou a ocupação paterna de forma mais simplificada se compararmos com a pesquisa de1998/ 1999. Assim, os agrupamentos por ocupação, nos cursos de FFLCH, se referem apenas à Legenda 1.

Legenda 1 - Outros: comerciante, aposentado, estudante, autônomo/não respondeu; PNB - profissional de nível básico; PNS - profissional de nível superior; PNM - profissional de nível médio.

Legenda 2 - DL - prendas do lar; PL - profissional liberal (médico, advogado, etc.); C/A - comerciante autônomo; D/P/P/G diretor presidente, pecuarista, gerente; PNS - profissional de nível superior (publicitário, professor universitário); Outros: bolsista, estagiário, estudante, aposentado; PD - profissional doméstico (empregada doméstica, motorista particular); PBQ profissional de baixa qualificação (mecânico, alfaiate); PNM - profissional de nível médio (bancário, técnico de informática); $\mathrm{PAQ}$ - profissional com alguma qualificação (digitador, ferramenteiro); NR - não respondeu.

10 Os porcentuais dos cursos da FFLCH/USP não estão discriminados, pois na pesquisa de 1997 as categorias foram analisadas de maneira mais simplificada.
As funções de menor prestígio social e, portanto, com baixa remuneração - Profissional de Nível Básico (PNB) - ou seja, Profissional Doméstico (PD), Profissional de Baixa Qualificação (PBQ) e Profissional com Alguma Qualificação (PAQ) - são mais freqüentes entre os pais dos alunos dos cursos de Biblioteconomia $(18,6 \%, 7 \%, 16,3 \%)$, Pedagogia $(10,3 \%, 9,6 \%, 11,9 \%)$, Contabilidade $(6,4 \%, 8,6 \%, 16,7 \%)$, Letras $(25,4 \%)$, e Ciências Sociais (25,4\%). ${ }^{10}$ As ocupações de nível médio são mais presentes entre os 
pais dos alunos dos cursos de Artes Plásticas $(25,5 \%)$, Jornalismo $(23,2 \%)$, Artes Cênicas $(23,8 \%)$, Publicidade $(21,9 \%)$ e Direito $(20,9 \%)$.

Em relação aos calouros (Tabela 14), os cursos que apresentam maior número de famílias chefiadas por profissionais com ocupação privilegiada - Diretor/Presidente/Pecuarista/Gerente (D/P/P/G), Profissional Liberal (PL) e Profissional de Nível Superior (PNS) - são Direito (10,6\%, 32,1\%, $17,4 \%)$, Editoração $(7,1 \%, 46,2 \%, 23,1 \%)$,
Psicologia (16,4\%, 32,8\%, 11,5\%), Administração (16\%, 22,1\%, 24,5\%), Relações Públicas $(7,4 \%, 25,9 \%, 22,2 \%)$ e Jornalismo (5\%, 30\%, 25\%). Por outro lado, os calouros cujos pais desempenham atividades de pouco prestígio social - Profissional Doméstico (PD), Profissional de Baixa Qualificação (PBQ) e Profissional com Alguma Qualificação (PAQ) - se encontram nos cursos de Biblioteconomia (18,6\%, 7\%, 16,3\%), Pedagogia $(10,3 \%, 9,6 \%, 11,9 \%)$ e Contabilidade $(6,8 \%, 8,6 \%, 16,7 \%)$.

\section{Tabela 14 - Distribuição dos estudantes de Humanidades - calouros - da USP, segundo curso e ocupação paterna - 1997-1999 (em \%)}

\begin{tabular}{|c|c|c|c|c|c|c|c|c|c|c|c|}
\hline Deupacaso & $\mathrm{DL}$ & PL & CIA & D/P/P/G & PNS & Outros & PD & $P B Q$ & PNM & $\mathrm{PAQ}$ & NR \\
\hline Administraçâo & 0,0 & 22,1 & 10,4 & 16,0 & 24,5 & 3.1 & 2,5 & $3, \overline{7}$ & 17.8 & 3.7 & 0,0 \\
\hline Economia & 0.0 & 22,5 & 10.6 & 11.9 & 26.5 & 4,6 & 1,3 & 5,3 & 15,9 & 5,3 & 0,0 \\
\hline Contabilidada & 0,0 & 12,0 & 19,4 & 8.3 & 20,4 & 2.8 & 9,3 & 1,9 & 15,7 & 10,2 & 0,9 \\
\hline Direito & 0,0 & 32,1 & 8,0 & 10,6 & 17,4 & 3,4 & 3,9 & 3,1 & 19,9 & 4,7 & 0,0 \\
\hline Psicologia & 0,0 & 32,8 & 6,6 & 16,4 & 11,5 & 3,3 & 4,9 & 4,9 & 19.7 & 1,6 & 0,0 \\
\hline Arquitetura & 0,0 & 39.2 & 5,4 & 9.2 & 17,7 & 1.5 & 2.3 & 5,4 & 13.1 & 6.9 & 0,8 \\
\hline Pedagogia & 0,0 & 17,1 & 14,5 & 6.8 & 12,8 & 8,5 & 12,0 & 9,4 & 6,0 & 12,8 & 0,0 \\
\hline Jornalismo & 0,0 & 30.0 & 15,0 & 5.0 & 25,0 & 2,5 & 5,0 & 0,0 & 17.5 & 2.5 & 0,0 \\
\hline Editoraçăo & 0,0 & 46,2 & 0,0 & 7,7 & 23,1 & 0,0 & 15,4 & 0,0 & 7,7 & 0,0 & 0,0 \\
\hline Turismo & 0,0 & 19.0 & 9,5 & 4.8 & 23,8 & 4,8 & 4,8 & 4,8 & 23.8 & 4.8 & 0,0 \\
\hline Publicidade & 3,1 & 40,6 & 6,3 & 18.8 & 18,8 & 6,3 & 0,0 & 0,0 & 9.4 & 0,0 & 0,0 \\
\hline Biblioteconomia & 0,0 & 3.7 & 11,1 & 3.7 & 38,3 & 3.7 & 18,5 & 18,5 & 3.7 & 3.7 & 0,0 \\
\hline Artes Plasticas & 0,0 & 0,0 & 0,0 & 0.0 & 0,0 & 0,0 & 0,0 & 0,0 & 0.0 & 0,0 & 0,0 \\
\hline Artes Cênicas & 0,0 & 22,7 & 18,2 & 9.1 & 18,2 & 9.1 & 4,5 & 4,5 & 13.6 & 0,0 & 0,0 \\
\hline Rádio/TV & 0,0 & 20,0 & 6,7 & 20,0 & 20,0 & 0,0 & 0,0 & 13,3 & 13,3 & 6.7 & 0,0 \\
\hline Cinema & 0,0 & 33.3 & 16,7 & 0.0 & 33,3 & 0,0 & 0,0 & 0,0 & 16.7 & 0.0 & 0,0 \\
\hline Relaćóes Públicas & 0,0 & 25.9 & 11,1 & 7.4 & 2,2 & 3.7 & 3.7 & 3,7 & 7.4 & 14.8 & 0,0 \\
\hline Música & 0,0 & 42,9 & 0,0 & 4,8 & 14,3 & 0,0 & 0,0 & 4,8 & 23,8 & 9,5 & 0,0 \\
\hline
\end{tabular}

Poderíamos inferir, a partir dessa análise, que estamos diante de um estudantado altamente diferenciado no que se refere à composição e ao volume de recursos sociais?

\section{Uma tentativa de classificação}

A partir desses comentários sentimos a necessidade de sistematizar melhor as diferenças e semelhanças do público universitário. Nossa atenção, pois, volta-se para um esforço de organizar os cursos segundo critérios sociais e acadêmicos de seus estudantes. Dessa forma, conseguiremos obter uma análise relacional dos dados atualizando e problematizando as informações sobre o público universitário.
A análise descritiva que fizemos oferece sugestões de associação de alguns dados como indicadores de hierarquização acadêmica e social. Como foi dito anteriormente, indicadores como renda, ocupação e instrução paterna e materna, relacionados com fatores como idade do aluno e ano de conclusão do ensino médio e período de curso, fornecem indícios de tendências de trajetórias entre os alunos.

Os indicadores analisados nos servem de apoio para criar três classes de cursos: os seletos, os intermediários e os populares. ${ }^{11}$ Para construir tal classificação, vamos utilizar as freqüências de algumas tabelas. O ponto central da análise é identificar os porcentuais reveladores de tendências que caracterizam esse ou aquele curso na categoria dos seletos, do intermediários ou

\footnotetext{
É importante ressaltar que essas denominações não encerram desprestígio ou julgamento de valor sobre a qualidade dos cursos nem de seu corpo docente ou discente.
} 
dos populares. Esse procedimento exigirá a criação, para cada uma dessas variáveis, de índices que definam os limites de cada grupo.

Vale ressaltar que as variáveis renda familiar e ocupação paterna referem-se especificamente a indicadores econômicos e de status da posição social ocupada pelos pais dos alunos. Em outras palavras, são indicadores do volume do capital econômico e social detido pela famílias dos estudantes. A instrução paterna e a materna e o conhecimento de idiomas são responsáveis pelo cálculo da composição e volume de capital cultural herdado pelo aluno. Grosso modo, capital econômico, capital social e capital cultural são indicadores materiais e objetivos das disposições de habitus dos estudantes, ou seja, são os elementos de ordem estrutural que ajudam a observar as diferenças de origem entre os grupos de estudantes.

Por outro lado, variáveis como idade, ano de conclusão do ensino médio e período de curso são indicadores temporais que apontam para o sentido das trajetórias sociais e acadêmicas dos estudantes. São úteis para dimensionar as tendências de mobilidade, dificuldades ou vantagens que os alunos detêm ao ingressar na universidade. São variáveis que só se tornam significantes quando associadas a referentes mais objetivos, como o volume e a composição do capital econômico e cultural dos alunos.

\section{Renda familiar}

12 Para proceder a essa classificação, consideramos cursos seletos, no item renda familiar, os que na soma das faixas de renda mais alta e faixas de renda intermediária garantem um porcentual significativo. Por exemplo, o curso de Direito entre os veteranos $37 \%$ - concentram-se na faixa acima de $\mathrm{R} \$ 5,2$ mil e $27,4 \%$, na faixa de $\mathrm{R} \$ 2,6$ mil a $\mathrm{R} \$ 5,2$ mil obtendo uma soma de $64,4 \%$ nas faixas com maior volume de renda. Outro exemplo, o curso de Contabilidade, no item instrução paterna está sendo considerado como curso popular, pois a concentração de capital cultural encontra-se, nos níveis de instrução não distintivo. Entre os veteranos desse curso $34,3 \%$ possuem pais na categoria educação básica: $19,4 \%$ na categoria educação média, soma $=53,7 \%$. renda familiar seja problemático, pois sua estimativa é sempre muito subestimada, ele serve como uma referência se analisado comparativamente a outros indicadores. Procedemos, então, da seguinte maneira:

- Cursos seletos: aqueles em que $30 \%$ ou mais dos alunos estão na faixa de renda acima de $\mathrm{R} \$ 5,2 \mathrm{mil}$;

- Cursos intermediários: aqueles em que $25 \%$ ou mais dos alunos estão na fai$x a$ de renda $\mathrm{R} \$ 2,6$ mil a $\mathrm{R} \$ 5,2$ mil;

- Cursos populares: aqueles em que $30 \%$ ou mais dos alunos estão nas faixas de renda abaixo de $\mathrm{R} \$ 2,6$ mil. $^{12}$

\section{Ocupação paterna}

O critério de classificação ocupacional utilizado leva em conta o grau de instrução necessário para o desempenho da ocupação, o status social e a renda adquirida estimada. Assim, consideramos:

- Cursos seletos: aqueles em que $20 \%$ ou mais dos pais são profissionais liberais, em que $20 \%$ ou mais dos pais exercem profissões de nível superior e aqueles em que $10 \%$ ou mais dos pais exercem cargos de direção/presidência;

- Cursos intermediários: aqueles em que $20 \%$ ou mais dos pais são profissionais de nível médio, em que $20 \%$ dos pais exercem profissões de nível superior e aqueles em que $10 \%$ ou mais dos pais são comerciantes;

- Cursos populares: aqueles em que $20 \%$ ou mais dos pais são profissionais de nível básico e em que $20 \%$ dos pais são profissionais de nível médio.

\section{Instrução paterna}

Embora, atualmente, o diploma universitário tenha deixado de ser um fiel indicador da origem social dos sujeitos, consideramos que quanto maior o nível de instrução do pai do aluno mais ele se aproxima dos grupos detentores do capital cultural prestigiado. Assim, denominamos:

- Cursos seletos: aqueles em que 50\% ou mais dos pais possuem instrução superior, incluindo pós-graduação;

- Cursos intermediários: aqueles em que $25 \%$ ou mais dos pais possuem nível de instrução médio;

- Cursos populares: aqueles em que $25 \%$ ou mais dos pais possuem nível de instrução básico (analfabeto e primeiro grau).

\section{Instrução materna}

Sabe-se que sobre os homens repousa uma maior cobrança em relação à profissionalização. Às mulheres, só recentemente vem sendo abertas as mesmas possibilidades. Assim, denominamos: 
- Cursos seletos: aqueles em que $50 \%$ ou mais das mães possuem formação superior, incluindo pós-graduação;

- Cursos intermediários: aqueles em que $25 \%$ ou mais das mães possuem nível de instrução médio;

- Cursos populares: aqueles em que $25 \%$ ou mais das mães possuem nível de instrução básico (analfabeto e primeiro grau).

\section{Conhecimento de idiomas}

Partimos do pressuposto de que o conhecimento de idiomas é um diferencial social. O hábito de falar línguas estrangeiras exige estímulo, dedicação e condições financeiras e, portanto, aqueles que manejam bem este distintivo capital cultural são, na maioria das vezes, provenientes de famílias que tiveram a oportunidade de proporcionar um estudo extra-escolar a seus filhos. Consideramos:

- Cursos seletos: aqueles em que $50 \%$ ou mais dos alunos falam fluentemente outro idioma;

- Cursos intermediários: aqueles em que $25 \%$ ou mais dos alunos falam fluentemente um outro idioma;

- Cursos populares: aqueles em que $30 \%$ ou mais dos alunos não responderam a essa questão.

\section{Idade}

Consideramos que os alunos que ingressaram no curso superior logo após concluir o ensino médio possuem uma trajetória educacional sem interrupções; o que reflete uma vida acadêmica anterior protegida e orientada em direção à profissionalização. Esta situação remete à presença de uma retaguarda familiar que assegura a permanência do estudante nos bancos escolares. Classificamos os cursos segundo a faixa etária de seus alunos. Assim, denominamos:

- Cursos seletos: aqueles em que $70 \%$ ou mais dos alunos estão na faixa etária de 17 a 24 anos;

- Cursos intermediários: aqueles em que $70 \%$ ou mais dos alunos estão nas faixas etárias de 17 a 24 anos e de 25 a 30 anos;
- Cursos populares: aqueles em que $50 \%$ ou mais dos alunos possuem mais de 25 anos.

\section{Ano de conclusão do ensino médio}

Consideramos que os alunos que não ingressaram na universidade logo após a conclusão do ensino médio têm toda a chance de ter sofrido algum tipo de dificuldade. A maior dificuldade reside na falta de uma retaguarda familiar e econômica que garanta os custos emocionais e financeiros que envolvem o processo de formação profissional.

Um ambiente familiar que estimule o desenvolvimento pessoal e profissional do indivíduo ou mesmo que retarde a responsabilidade do auto-sustento é um importante elemento de diferenciação social. Denominamos:

- Cursos seletos: aqueles em que $70 \%$ ou mais dos alunos concluíram o ensino médio nos anos de 1998/1997/ 1996, ou seja, os alunos que demoraram apenas de um a dois anos para ingressar na universidade;

- Cursos intermediários: aqueles em que $50 \%$ ou mais dos alunos concluíram o ensino médio nos anos de 1997/1996/ $1995 / 1994$, ou seja, aqueles que tiveram seus planos de ingresso na universidade postergados por, no máximo, quatro anos;

- Cursos populares: aqueles em que mais de $20 \%$ dos alunos demoraram quatro anos ou mais para ingressar na universidade. ${ }^{13}$

Para melhor apreciação das informações apresentamos, em seguida, o quadro referente aos indicadores utilizados. Apontamos os cursos de clientela com alto volume de capital econômico, capital social e capital cultural, bem como os que se distinguiram por apresentar um número significativo de alunos que, segundo as variáveis temporais, apontam no sentido de uma trajetória tranqüila, sem interrupções de ordem social e financeira. Consideramos intermediários os cursos cujos alunos indicaram volume e composição de capital econômico, capital social e cultural em níveis relativamente pouco distintivos. Por último, apontamos os cursos com clientela com baixo volume nos indicadores sociais e acadêmicos.

\footnotetext{
${ }^{13}$ Cabe aqui uma observação. Em muitos casos a ocupação tardia dos bancos universitários pode ser conseqüência de fatores econômicos, mas pode refletir também mudanças na trajetória profissional dos alunos, ou até uma experiência bem-sucedida em termos da aquisição de outro diploma. Uma análise mais detalhada pode nos ajudar a esclarecer estas hipóteses.
} 


\section{Quadro classificatório}

\begin{tabular}{|c|c|c|c|c|c|c|c|c|}
\hline Ocupacâo & Renda & Ocupacåo & Instruc. Pai & Instruc. Mãe & Idioma & Idade & Periodo & Conclusáo \\
\hline Adininistuacăo & $x$ & $x$ & $x$ & $x$ & $x$ & 0 & 0 & $x$ \\
\hline Eccnomia & $x$ & $x$ & $x$ & 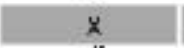 & $\mathrm{x}$ & $x$ & 0 & $x$ \\
\hline Contabilidade & 0 & $\#$ & $\#$ & $\#$ & $\#$ & $\#$ & $\#$ & \# \\
\hline Direito & $x$ & $x$ & $x$ & $x$ & $x$ & $x$ & 0 & $x$ \\
\hline Psicologia & 0 & $x$ & $x$ & $x$ & $x$ & $x$ & $x$ & 0 \\
\hline Arquitetura & $x$ & $x$ & $x$ & $x$ & $x$ & 0 & $x$ & $x$ \\
\hline Pedagoga & $\#$ & \# & \# & $\#$ & \# & 0 & \# & \# \\
\hline Jornalismo & 0 & $x$ & $x$ & $x$ & $x$ & $x$ & 0 & $x$ \\
\hline Ecditoração & $x$ & $x$ & $x$ & 0 & 0 & 0 & $x$ & $x$ \\
\hline Turismo & 0 & 0 & $x$ & $x$ & $\mathrm{x}$ & $x$ & $\#$ & $x$ \\
\hline Publiciclade & 0 & $x$ & $\mathrm{x}$ & $x$ & $x$ & $\mathrm{x}$ & \# & $x$ \\
\hline Biblioteconomia & \# & $\pi$ & $\#$ & F & 퓨 & \# & 0 & \# \\
\hline Artes Plásticas & $\#$ & 0 & $x$ & $x$ & $x$ & 0 & $\mathrm{x}$ & $?$ \\
\hline Artes Cênicas & \# & 0 & $x$ & $x$ & $\mathrm{x}$ & $x$ & $x$ & 0 \\
\hline RàdiolTV & $x$ & $x$ & $\mathrm{x}$ & $x$ & $\mathrm{x}$ & D & $x$ & $x$ \\
\hline Cinema & 0 & $x$ & $x$ & $x$ & $x$ & $x$ & $x$ & $x$ \\
\hline Relaçōes Públicas & $x$ & $x$ & $x$ & $x$ & $\mathrm{x}$ & $x$ & $x$ & $x$ \\
\hline Música & $\#$ & & $\mathrm{x}$ & $x$ & $x$ & $x$ & $x$ & $x$ \\
\hline Ciếncias Sociais & \# & 0 & \# & \# & \# & 0 & \# & $?$ \\
\hline Filosofia & $\#$ & 0 & \# & $\#$ & \# & \# & $\#$ & $?$ \\
\hline Geografia & \# & \# & \# & $\#$ & \# & \# & \# & $?$ \\
\hline História & \# & 0 & \# & \# & \# & 0 & \# & $?$ \\
\hline Letras & $\#$ & $?$ & \# & $\#$ & \# & 0 & \# & $?$ \\
\hline
\end{tabular}

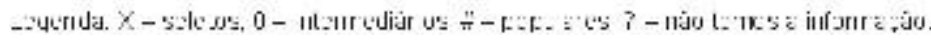

Continuando ao trabalho de classificação, é interessante observar a relação abaixo, pois reflete um esforço de posicionar os cursos em ordem decrescente, segundo o volume dos recursos sociais de seus estudantes. Estamos considerando uma hierarquização entre esses recursos. Ou seja, o capital econômico ou seu correspondente "faixas de renda" possui, em nossa classificação, um peso maior, se comparado a outros recursos, como capital social (ocupação) e capital cultural (nível de instrução).

\section{Seletos \\ (ordem decrescente)}

- Alta concentração em todas as formas de capital (capital econômico, capital social e capital cultural):

Direito - renda, ocupação, instrução pai, instrução mãe, idioma, idade, conclusão;

Administração - renda, ocupação, instrução pai, instrução mãe, idioma, conclusão;

Arquitetura - renda, ocupação, instrução pai, instrução mãe, idioma, período, conclusão;

Rádio/TV - renda, ocupação, instrução pai, instrução mãe, idioma, período, conclusão;
Editoração - renda, ocupação, instrução pai, período, conclusão;

Relações Públicas - renda, ocupação, instrução pai, instrução mãe, idade, período, conclusão.

- Alta concentração em duas formas de capital (capital social e capital cultural):

Psicologia - ocupação, instrução pai, instrução mãe, idioma, idade, período;

Economia - ocupação, instrução pai, instrução mãe, idioma, idade, conclusão;

Cinema - ocupação, instrução pai, instrução mãe, idioma, idade, período, conclusão;

Jornalismo - ocupação, instrução pai, instrução mãe, idioma, idade, conclusão;

Publicidade - ocupação, instrução pai, instrução mãe, idioma, idade, conclusão.

- Alta concentração somente em capital cultural:

Artes Cênicas - instrução pai, instrução mãe, idade, período;

Música - instrução pai, instrução mãe, idade, período, conclusão;

Turismo - instrução pai, instrução mãe, idioma, idade, conclusão; 
Artes Plásticas - instrução pai, instrução mãe, idioma.

\section{Intermediários \\ (ordem decrescente)}

- Média concentração em duas formas de capital (capital econômico e capital social):

Turismo - renda, ocupação;

Contabilidade - renda, ocupação;

Jornalismo - renda, período;

Publicidade - renda;

Psicologia - renda, conclusão;

Relações Públicas - renda;

Cinema - renda.

- Média concentração somente em uma forma de capital (capital social):

Artes Plásticas - ocupação, idade;

Artes Cênicas - ocupação, conclusão;

Música - ocupação;

História - ocupação, idade;

Filosofia - ocupação;

Ciências Sociais - ocupação, idade.

- Média concentração em uma forma de capital (capital cultural):

Editoração - instrução mãe, idade.

Os cursos a seguir relacionados se destacam por apresentar índices relativamente pouco distintivos no que se refere a algumas variáveis. Vejamos: Letras idade; Rádio/TV - idade; Pedagogia - idade; Arquitetura - idade; Biblioteconomia - período; Direito - período; Economia período.

\section{Populares \\ (ordem decrescente)}

- Baixa concentração em todas as formas de capital (capital econômico, capital social e capital cultural):

Biblioteconomia - renda, ocupação, instrução pai, instrução mãe, idioma, idade, conclusão;

Pedagogia - renda, ocupação, instrução pai, instrução mãe, idioma, período, conclusão.

- Baixa concentração em duas formas de capital (capital econômico e capital cultural):
Geografia - renda, instrução pai, instrução mãe, idade, período;

Letras - renda, instrução pai, instrução mãe, período;

História - renda, instrução pai, instrução mãe, período;

Filosofia - renda, instrução pai, instrução mãe, idade, período;

Ciências Sociais - renda, instrução pai, instrução mãe, período;

- Baixa concentração somente em uma forma de capital (capital cultural):

Contabilidade - instrução pai, instrução mãe, idioma, idade, período, conclusão.

- Baixa concentração somente em uma forma de capital (capital econômico):

Artes Plásticas - renda:

Artes Cênicas - renda, idioma:

Música - renda, idioma.

O curso de Editoração se destaca por apresentar alto índice de alunos que não falam outro idioma; os de Turismo e Publicidade, por ser bastante significativo o número de matrículas no período noturno.

\section{A classificação}

A classificação salientou as diferenças de recursos sociais das famílias e as trajetórias acadêmicas dos estudantes investigados. A partir da composição e do volume dos recursos dos alunos - capital econômico, capital social e capital cultural - elaboramos uma classificação dos cursos identificando as posições de prestígio e privilégios de suas famílias.

Consideramos como indicadores determinantes na formação do habitus e das disposições socioacadêmicas dos alunos as variáveis de natureza material e objetiva. Renda, ocupação e instrução paterna e materna são indicadores que correspondem respectivamente a capital econômico, capital social e capital cultural, segundo uma ordem hierárquica decrescente de poder e privilégios. Para nós os cursos identificados como os mais seletos entre os pesquisados são os que apresentam altas concentrações de recursos econômicos, sociais e culturais. Ou seja, são os que se destacam em todos os três indicadores estruturais de distinção social. Por outro lado, os cursos classificados como os mais populares são os que 
indicaram baixa concentração nos três indicadores estruturais distintivos.

Na posição intermediária, destacamos os cursos que se encontram com índices medianos nas variáveis renda e ocupação paterna. Eles se destacam por apresentar um número significativo de alunos com volume de capital econômico e capital social em níveis relativamente distintivos ou os que apresentam altos índices somente em capital cultural.

É importante ressaltar que observamos uma correspondência entre os cursos mais seletos e aqueles que levam a carreiras com boas expectativas de ganho financeiro e status social. São cursos que se destacam também por apresentar grande competitividade nos vestibulares. Por essas características, são altamente seletivos e destinados a um pequeno grupo de estudantes (Direito, Administração, Arquitetura, Rádio/TV, Editoração, Relações Públicas).

Por outro lado, os cursos populares são os que oferecem baixas expectativas de profissionalização, já que levam a carreiras pouco valorizadas no mercado de trabalho. Com expectativa de baixos salários e estreitas oportunidades de empregabilidade em postos de prestígio, os estudantes desses cursos possuem uma característica em comum: são os mais habilitados a se dedicar ao magistério, carreira com baixo status social (Pedagogia, Biblioteconomia, Letras, Geografia, Filosofia, História e Ciências Sociais).

Observamos também uma outra correspondência importante, e essa refere-se à questão de gênero. Ou seja, verificamos que existe uma acentuada tendência dos homens escolherem os cursos classificados como seletos. Segundo nossas informações, os cursos preferidos pela clientela masculina são os denominados como seletos. Notamos que este fato é comum entre calouros e veteranos. Apenas o curso de Direito parece indicar um certo equilíbrio entre os sexos, mas é clara a pequena vantagem para o sexo masculino.

Todavia, no que se refere aos cursos populares observamos a tendência quase inversa. Ou seja, existe uma certa preferência do público feminino pelos cursos populares. Embora encontremos exceções, é interessante observar que grande parte do corpo discente desses cursos é constituído por mulheres. São os casos dos cursos de Pedagogia, Letras e Biblioteconomia. Salientamos porém, que os cursos de Geografia e Filosofia nas últimas décadas parecem estar atraindo uma clientela masculina. Os cursos de História e Ciências Sociais apresentam dados equilibrados oferecendo um número semelhante de alunos do sexo feminino e masculino. Em recente trabalho foi possível observar uma certa masculinização nesses cursos e uma estratégia de acumular mais de um diploma universitário entre esses alunos (Setton, 1998).

Assim, caberia perguntar se a hierarquia observada entre os cursos de humanidades sofre um desdobramento hierárquico nas diferenças de sexo? Ou seja, a correspondência entre cursos seletos e público masculino e cursos populares e clientela feminina seria mais uma distinção dentro do campo do ensino superior e nos destinos profissionais?

Consideramos que a principal tarefa das pesquisas empíricas é retratar o mais fielmente possível uma dada realidade. Devem contribuir para esclarecer as diferenças entre os cursos e clientelas e sobretudo subsidiar formas políticas de atuação. A nosso ver é problemático homogeneizar orientações e avaliações de alunos com condicionamentos sociais diferenciados e que possuem distintas perspectivas quanto a sua formação profissional. No caso da realidade investigada, ao tomarmos ciência dos problemas específicos de cada unidade, curso e clientela, impõe-se a elaboração de medidas que assegurem a heterogeneidade do estudantado ao acesso equânime ao produto universitário. Os dados desta pesquisa nos instigam a reconsiderar a simplificação de que a Universidade de São Paulo é privilégio de uma elite; e nos forçam a indagar se ela está atenta aos impedimentos de um melhor aproveitamento de seus cursos pelos estudantes de origem social mais simples.

Para concluir, gostaríamos de ressaltar que o esforço de classificação ora elaborado deve ser visto como uma leitura aproximada de uma hierarquia acadêmica dos cursos e das clientelas investigadas. Não pretende ser mais que um ensaio para compreender as diferentes posições ocupadas pelos cursos no espaço universitário. Não pode ser visto como uma hierarquização rígida, pois essa seria incapaz de dar conta da complexidade sociológica do campo universitário brasileiro. Ao propô-lo, procuramos, sobretudo, 
destacar a importância das variações de composição da clientela, tentando contribuir com o falso conceito de elitização do ensino superior. Para nós, a questão do acesso seletivo ao ensino superior parece ocultar o verdadeiro gargalo das oportunidades educacionais. É sabido que as oportunidades de inserção nos mais altos níveis de ensino é determinado no início das trajetórias acadêmicas dos alunos. A falsa discussão sobre as poucas oportunidades de acesso aos bancos universitários encobre as desigualdades estruturais da sociedade capitalista, bem como o poder diferenciado dos diplomas e carreiras, suas estratégias de conquistas e utilização.

\section{Referências bibliográficas}

BOURDIEU, P. Les trois états du capital culturel. Actes de la Recherche en Sciences Sociales, Paris, n. 30, p. 3-6, nov. 1979a.

. Le capital social: notes provisoires. Actes de la Recherche en Sciences Sociales, Paris, n. 31, p. 2-3, jan. 1980.

. La distinction: critique sociale du jugement. Paris: Minuit, 1979b.

Homo academicus. Paris: Minuit, 1984.

Pierre Bourdieu. Renato Ortiz (Org.). São Paulo: Ática, 1983.

BOURDIEU, P.; BOLTANSKI, L.; SAINT-MARTIN, M. As estratégias de reconversão. In: DURAND, J. C. (Org.). Educação e hegemonia de classe: as funções ideológicas da escola. Rio de Janeiro: Zahar, 1979.

BOURDIEU, P.; PASSERON, J. C. Los estudiantes y la cultura. Barcelona: Labor, 1967. (Nueva colcción labor).

A reprodução: elementos para uma teoria do sistema de ensino. Rio de Janeiro: Francisco Alves, 1982.

CASTRO, C. L. Monteiro de et al. Caracterização socioeconômica do estudante universitário. Rio de Janeiro: MEC, 1968.

CATANI, A.; NOGUEIRA, M. A. Escritos de educação: Pierre Bourdieu. Petrópolis: Vozes, 1998.

ERLICH, Valérie. Les nouveaux étudiants: un groupe social en mutation. Paris: Armand Colin, 1998.

GALLAND, O.; OBERTI, M. Les étudiants. Paris: Découvert, 1996.

GOUVEIA, Aparecida Joly. Democratização do ensino superior. Revista Brasileira de Estudos Pedagógicos, Rio de Janeiro, v. 50, n. 112, p. 232-244, out./dez. 1968.

. Origem étnica e situação socioeconômica dos universitários paulistas. Revista

de Administração de Empresas, Rio de Janeiro, v. 12, n. 1, p. 71-80, jan./mar. 1972.

A GREVE nas universidades. O Estado de S. Paulo, São Paulo, 8/5/2000. Editorial.

GRIGNON, C.; GRUEL, L. La vie étudiante. Paris: PUF, 1999.

O IMPASSE nas universidades. O Estado de S. Paulo, São Paulo, 18/5/2000. Editorial.

LAURENS, Jean-Paul. 1 sur 5000: la réussite scolaire en milieu populaire. Toulouse:

Presses Universitaires du Mirail, 1992. 
NOGUEIRA, Maria Alice et al. Família e escola: trajetórias de escolarização em camadas médias e populares. Petrópolis: Vozes, 2000.

PELA universidade pública. O Estado de S. Paulo, São Paulo, 23/5/2000. Editorial.

PRANDI, Reginaldo. Os futuros cientistas sociais: algumas características, avaliações e expectativas dos alunos de Ciências Sociais da Universidade de São Paulo. São Paulo: Departamento de Ciências Sociais/USP, 1980.

. Os favoritos degradados: ensino superior e profissões de nível universitário noBrasil hoje. São Paulo: Loyola, 1982.

SANTOS, Cássio M. O perfil socioeconômico dos candidatos e dos matriculados pelos vestibulares da UNESP em 1992: o grau de elitização dos cursos de Marília e Araçatuba. Marília, 1996. Dissertação (Mestrado) - Universidade Estadual Paulista.

SCHWARTZMAN, Simon. A trajetória acadêmica e profissional dos alunos da USP: posição social da família e experiência universitária: análises preliminares - AP3/92. São Paulo: Nupes/USP, 1992.

SETTON, Maria da Graça J. Os projetos de profissionalização dos estudantes da FFLCH - USP: algumas considerações. Caxambu, 1998. (Trabalho apresentado no $21^{\circ}$ Encontro Anual da ANPEd).

Recebido em 12 de julho de 2000.

Maria da Graça Jacintho Setton, doutora em Sociologia pela Faculdade de Filosofia, Letras e Ciências Humanas da Universidade de São Paulo (FFCLH/USP), é professora da Faculdade de Educação e pesquisadora do Núcleo de Apoio aos Estudos de Graduação (Naeg) dessa universidade.

\section{Abstract}

The purpose of this paper is to propose a reflexion about a possible hierarchization of the universitaires humanities courses of USP, based on the analysis of the social origin and academic trajectory of it's students. The analysis of the social culturals characteristics of the students showed us the existence of a hidden classification in the studied courses. Moreover that, the analysis demonstrated that it exists a correspondence between the differences of economics ressources of the students and the demand for certains courses and careers. It is an effort on the understanding of the university field and on the understanding of parts of the agents who compose it.

Keywords: universitary courses; universitary students; social origin; academic trajectory. 